\title{
Deformation Regulations and Failure Mechanism of High and Steep Layered Rock Slopes with Upper Steep and Lower Gentle Style Induced by Step-by- Step Excavations
}

\section{Zhiquan Yang}

Kunming University of Science and Technology - Lianhua Campus: Kunming University of Science and Technology

\section{Xianglong Fan}

Kunming University of Science and Technology - Lianhua Campus: Kunming University of Science and Technology

\section{Yi Yang}

Kunming University of Science and Technology - Lianhua Campus: Kunming University of Science and Technology

\section{Kepeng Hou}

Kunming University of Science and Technology - Lianhua Campus: Kunming University of Science and Technology

Jun Du ( $\sim$ dujun0605@126.com)

Kunming University https://orcid.org/0000-0001-5636-4952

\section{Xinggui Chen}

The Third Engineering Co., Ltd. of China Railway Seventh Bureau Group Corporation

\section{Yapeng Mi}

The Third Engineering Co., Ltd. of China Railway Seventh Bureau Group Corporation

\section{Chunping Jiang}

The Third Engineering Co., Ltd. of China Railway Seventh Bureau Group Corporation

Jie Jiang

Yunnan Institute of Geological Environment Monitoring

\section{Yongfa Guo}

Kunming Survey, Design and Research Institute Co., Ltd. of CREEC

\section{Research Article}

Keywords: step-by-step excavations, high and steep layered rock slopes, numerical analysis, deformation regulations, failure mechanism 
Posted Date: September 29th, 2021

DOl: https://doi.org/10.21203/rs.3.rs-931050/v1

License: (c) (i) This work is licensed under a Creative Commons Attribution 4.0 International License. Read Full License 


\section{Abstract}

High and steep layered rock slopes with upper steep and lower gentle style is a typical layered rock slope in Western region of China. Deformation regulations and failure mechanism of this kind of slope induced by step-by-step excavations were investigated in this study. By FLAC ${ }^{3 \mathrm{D}}$, excavation process is simulated according to actual situation (the first three phases) and planned excavation order (the last two phases). For the first three phases, through comparing simulation results and actual slope form, rationality of the model has been checked. For the last two phases, failure characteristics have been analyzed by simulation results. During the whole process of excavation, deformation can be summarized as "slipbend-shear", and most dangerous slip surface of composite-style has been developed gradually into the slope. This research can provide theoretical support and guidance for the stability analysis, quantitative excavation design and pre-warning system of this type of slope in the process of western development in China.

\section{Introduction}

With the continuous expansion of resource exploitation, open-pit mining has gradually shifted to large mining depths and steep slopes, while the contradiction between output and instability of slope rock masses has highly increased(Tao et al. 2021). From 2007 to 2017, the accidents due to slope stability were 221 contributing to $31 \%$ of all open pit accidents and the major cause of accidents in Indian open pit mines(Satyanarayana and Budi 2019). From 1953 to 2004, 85 large and small landslides occurred within Haizhou open pit. The buildings and urban infrastructure around this open pit were damaged(Zhang 2009). From 1978 to 2016, 6 landslides occurred almost within the same area in Fushun West open pit. Traffic and production have been seriously affected(Gao 2017).

Therefore, for open mines, slope hazard assessment is an important part of controlling risk (Santos et al. 2019). It can not only eliminate the potential hazards of landslide in time, but also provide a reference for a preventive against landslide (Guo et al. 2020).

Currently hazard assessment for slopes are performed with different methods, including limit equilibrium method and numerical simulation method (Guo et al. 2020). Among these methods, limit equilibrium is an approximate, generally accepted method of analysis (Michalowski 2013) and it is also easily mastered by its simple theory-The stability of rock slopes depends on the shear strength generated along the sliding surface. (Deng and Li 2019, Wyllie and Mah 2004). Based on limit equilibrium method, many researchers analyze the stability of slope and prevent slope from failure(Botero et al. 2020, Chen et al. 2014, Deng et al. 2019, Zhou et al. 2019)

Limit equilibrium method is not always effective when coping with large complex rock slope, since it cannot consider the internal stress and strain relations in rock masses (Crosta and Agliardi 2003, Yang et al. 2012) . In contrast, numerical methods are more suitable for large complex problems(Chen et al. 2020, Eberhardt et al. 2004, Li et al. 2009, Liu et al. 2020). In particular, a large 3D physical modeling experiment 
can accurately provide enough information(Castro et al. 2007, Lai et al. 2015, Yifan et al. 2015), which can help engineers and researchers to better evaluate risks and study failure mechanism of the slope. The finite-difference (FDM), finite-element (FEM), and boundary-element (BEM) methods are representative methods for modeling(Gong and Tang 2017). Based on numerical methods, many complicate slope stability evaluations have been solved(Chen 2017, Liu et al. 2005, Sarkar et al. 2012, Zhu et al. 2011).

Recently, many researchers tried to solve slope stability using Artificial Neural Network (ANN) models. The parameters of slope and inventory maps are fed as an input to ANN models. Open mines in different areas are selected as training sites using random sampling. A feedforward back-propagation algorithm is implemented to analyze slope susceptibility(Lian et al. 2020, Vemulapalli and Mesapam 2021). Furthermore, more complicated artificial intelligence model has been built to forecast open-pit mine slopes stability in Vietnam(Bui et al. 2020). Although above models represent the future hotspots of open mine, they cannot reveal deformation regulations and failure mechanism of the slopes.

Compared to BEM and FEM, FDM is especially suited to simulate non-linear behaviour of solid materials and fracture problems(Jing 2003). In addition, the computational process based on FDM does not require storing lots of stiffness matrix(CHEN and XU 2009), which is suited to simulate large scale project. Therefore, FLAC ${ }^{3 \mathrm{D}}$, the widely used FDM software, is selected for modeling. FLAC ${ }^{3 \mathrm{D}}$ not only can calculate the stress and strain field, but can analyze the slope rock mass deformation of each part in the development of the time with the evolution(Wang et al. 2012), which can well apply to simulation of stepby-step excavation process. The possible internal deformation mechanism and regulations of slope rock masses are analyzed through four aspects: displacement, stress, velocity field and plastic zone distribution.

\section{Engineering Geological Conditions And Effect Of Excavation}

Jianshan phosphate mine, owned by Yunnan Phosphate Group, is located in Haikou Town, Xishan District, Kunming. It is about $42 \mathrm{~km}$ away from the main city of Kunming. The top of the slope is at an elevation of $2225.75 \mathrm{~m}$. Minimum erosion basis is at an elevation of $1883.15 \mathrm{~m}$. The height of slope is $342.6 \mathrm{~m}$. The dip of the slope, extending $200-250 \mathrm{~m}$ from the top of the slope, is distributed within the range of $35^{\circ}-50^{\circ}$, and the dip of the lower slope is $20^{\circ}-30^{\circ}$. As what is shown in Fig. 1 and Fig.2, the slope presents a structure of "upper steep and lower gentle".

Fig.1 Close-up view of high and steep layered rock slopes belonging to Jianshan phosphorite mine

\section{Engineering geological conditions}

Jianshan phosphate mine is located in the west side of Dian Lake, where is a typical alpine terrain. On the whole, the northern part of the terrain is steep, and the south is gentler. The elevation of slope gradually reduces from west to east. It is about $1200 \mathrm{~m}$ long along the strike orientation, with gullies in the northsouth direction. 
The geological cross section and specific distribution of strata and lithology in this area is shown in Fig.2 and Extended Fig.1.

Extended Fig.1 Specific distribution of strata and lithology

Fig.2 Geological cross section

Jianshan phosphate mine is located in the east section of northern flank of Xiangtiao Village anticline. Xiangtiao Village anticlinal structural belt is monoclinal in the east-west direction. Traction folds and broad folds are respectively developed in the east and west part of the area. At the same time, there are two thrust faults $F_{1-1}$ and $F_{1-2}$ parallel to the axis of Xiangtiao Village anticline. Both faults are generally in east-west direction, of which the $F_{1-1}$ thrust fault is the main fault in this area, with a dip direction of $330^{\circ}-20^{\circ}$, and the $F_{1-2}$ thrust fault has a dip direction of $340^{\circ}-360^{\circ}$. The distribution of the two faults is shown in Fig.3. By analyzing the rock core samples obtained by drilling at different elevation, it can be seen that the rock quality designation (RQD) in Jianshan phosphate mine area is about $7 \%-8 \%$. It shows that the intense tectonic movement leads to very fragmented slope rock masses in this area, as shown in Fig.3.

Fig.3 Rock samples by drilling in the area of Jianshan phosphorite mine

\section{Effect of excavation}

The intense step-by-step excavation has a very serious effect on the slope stability of Jianshan phosphate mine, which not only leads to the occurrence of many cracks in different positions of the slope, but also induces landslides and debris avalanche in local areas.

In 2007, the slope was extended to $2035 \mathrm{~m}$ with a vertical height of 191 meters, resulting in the development of a crack from east to west at the top of the slope, with a length of 200 meters, a width of $15 \mathrm{~mm}-500 \mathrm{~mm}$, and a visible depth of about 4 meters. In addition, it resulted in the development of floor heave at the toe of the slope, as shown in Fig.4. In order to ensure the safety of production, to the slope section above $2070 \mathrm{~m}$, the load reduction measure of excavation by steps was adopted: five benches (each bench is 30 meters high) were built in the elevation of $2070 \mathrm{~m}, 2100 \mathrm{~m}, 2130 \mathrm{~m}, 2160 \mathrm{~m}$ and $2190 \mathrm{~m}$, of which the width of $2160 \mathrm{~m}, 2130 \mathrm{~m}$ and $2100 \mathrm{~m}$ is $8 \mathrm{~m}$, the width of $2190 \mathrm{~m}$ is $4 \mathrm{~m}$ and the width of $2070 \mathrm{~m}$ is $12 \mathrm{~m}$.

After taking the above measures, the slope was excavated to $1935 \mathrm{~m}$. Based on field investigation, it can be found that, at present, on the benches in the elevation of $2070 \mathrm{~m}, 2010 \mathrm{~m}, 2130 \mathrm{~m}$ and $2190 \mathrm{~m}$, cracks almost along the strike appeared, with the maximum width of about $100 \mathrm{~cm}$ and the length ranging from several to tens meters. Uneven settlement happened in the most of the rock and soil masses on both sides of the cracks and landslide or debris avalanche has occurred, as shown in Fig. 5.

According to the layout of Jianshan phosphate mining enterprise, the mining slope shall be excavated to $1910 \mathrm{~m}$ and $1840 \mathrm{~m}$ respectively during the first and second mining projects. 
1. The crack at the top of the slope

2. Floor heave at the toe of the slope

Fig.4 Deformation and failure of Jianshan phosphorite mine excavated to $2035 \mathrm{~m}$

(1) A landslide happened in the bench at the elevation of $2070 \mathrm{~m}$

(2) A crack developed in the bench at the elevation of $2190 \mathrm{~m}$

Fig.5 Deformation and failure of Jianshan phosphorite mine excavated to 1935m (Present state)

\section{Analysis Of Deformation And Failure}

\section{Physico-mechanical parameters of rock mass}

Based on the results of laboratory rock physical mechanics tests and rock mass in-situ tests, the rock masses mechanical parameters of Jianshan phosphate rock slopes were reasonably estimated and selected through empirical estimation and engineering geological analogy (Table 1)(Du 2014). In FLAC ${ }^{3 D}$ numerical simulation, the rock mass material is simulated by using the Mohr-Coulomb model.

\section{Numerical model}

Based on the topographic features, geological cross section, and specific distribution of strata and lithology in this area, the original (before excavation) 3D mechanical model of the slope was established by FLAC $^{3 \mathrm{D}}$ (Fig.6). The 3D numerical model size is $1700 \mathrm{~m}$ ( $X$ direction, dip direction) $\times 1300 \mathrm{~m}$ ( $Y$ direction, strike) $\times 626 \mathrm{~m}$ ( $Z$ direction, height). It is divided into 325680 units and 341220 nodes. In the process of modeling, the slope is simplified. It can be seen from Fig.2, there is a hydromica clay layer with a thickness of $0.58-2 \mathrm{~m}$ in the middle of the ore body, which divides the ore body into upper and lower ore layers. Two thrust faults $F_{1-1}$ and $F_{1-2}$ located in the stratum with ore body. However, the stratum with ore body will be excavated. The hydromica clay layer and thrust faults have little influence on the final slope stability, so they are not considered in the numerical model. In the model, the free face is set as a free boundary, the bottom is set as a fixed constraint boundary $(z=1600 \mathrm{~m})$, and the surrounding is set as a one-way constraint boundary. Because the tectonic stress of slope surface is basically released, in the initial condition, the tectonic stress is not considered, but only the initial stress field generated by gravity stress is considered.

Fig.6 Original three-dimensional geological model of Jianshan phosphorite mine

\section{Each excavation stage}

The model is set according to its actual excavation situation and planned excavation order:

1. Stage 0. Original state of slope. 
2. Stage 1 . The slope is mined from the elevation of $2226 \mathrm{~m}$ to $2035 \mathrm{~m}$.

3. Stage 2. Firstly, the benches at the elevation of $2190,2160,2130,2100$ and $2070 \mathrm{~m}$ shall be unloaded by steps (the height of benches is $30 \mathrm{~m}$, except that the width of the benches at the elevation of $2190 \mathrm{~m}$ and $2070 \mathrm{~m}$ is $4 \mathrm{~m}$ and $12 \mathrm{~m}$ respectively, the width of the other three benches is $8 \mathrm{~m}$ ); then, the slope shall be excavated to the elevation of $1935 \mathrm{~m}$ (the actual excavation status of the slope at present).

4. Stage 3. From the elevation of $1935 \mathrm{~m}$ to $1910 \mathrm{~m}$, it completes the first mining project.

5. Stage 4. From the elevation of $1910 \mathrm{~m}$ to $1840 \mathrm{~m}$, it completes the second mining project.

Among the above five stages, the first three stages are completely set based on the actual excavation of the Jianshan phosphate rock slope, and the last two stages are planned according to layout of jianshan phosphate mining enterprise.

\section{Analysis Of Numerical Simulation Results}

\section{Analysis of actual excavation situation}

The rationality of the model parameters is checked through comparing simulation results and actual slope form, so as to correctly predict and evaluate the deformation phenomenon and regulations later.

(1) Stage 0. Original state of slope.

According to the analysis, the slope is in equilibrium in its original state. In the original state, the stress field of the slope is evenly distributed, which accords with that the stress field changing with depth. The stress gradually increases from the slope surface to the deep part, and the maximum compressive stress value is $11.8 \mathrm{MPa}$, which accords with that the stress is mainly caused by the self-weight stress of the rock masses in the original state, and the tensile stress appears at the terrain with abrupt change, the maximum value is about $0.27 \mathrm{MPa}$, as shown in Fig.7. Therefore, in the original state, the slope is in equilibrium and there is no abnormal response, the following analysis can be carried out.

1. Maximum principal stress nephogram

2. Minimum principal stress nephogram

Fig.7 Stress nephogram of the slope under the original condition

(2) Stage 1. The slope is mined from the elevation of $2226 \mathrm{~m}$ to $2035 \mathrm{~m}$.

From the beginning of production to 2007, the Jianshan phosphate rock slope was excavated from the top to an elevation of $2035 \mathrm{~m}$, which resulted in the development of a crack along the strike and floor heave at the toe of the slope.

It can be seen from Fig.8 (a) that after the excavation, the stress field of the original rock is redistributed. The rock masses in most areas are under compression, and the maximum compressive stress is $14 \mathrm{MPa}$. 
Tensile stress concentration zones appear on the top of slope, and the maximum tensile stress is $0.35 \mathrm{MPa}$. The direction of both the maximum principal stress (compressive stress) and the minimum principal stress (tensile stress) extends along the surface to the toe of the slope, and the tensile stress concentration zones appear at the toe of the slope. At the same time, the minimum principal stress nephogram also shows that after excavating, a large range of tensile stress zones appear on the top of the slope, and the rock masses are in tension, which causes it to undergo tensile failure to form tensile cracks. Under the effect of self-weight stress, the rock masses within a certain range of the free face have a tendency to slide along the rock layer, causing the lower unexposed rock to be bent and sheared by the upper rock. The analysis above explains the development of cracks on the top of the slope and floor heave at the toe of the slope under the action of actual excavation.

Fig.8 (b) reflects the change in slope displacement caused by the excavation at this stage: the rock masses in the $X$ (strike) and $Z$ (height) directions move significantly towards the excavation face. At the top of the slope, the displacement in the $X$ and $Z$ directions will cause the rock masses in the upper part of the slope to sink, and it is easy to form cracks along the strike. The maximum displacement in the $X$ direction is $2.5 \mathrm{~cm}$, and the direction is backward the excavation face; the maximum displacement in the $Z$ direction is $1.03 \mathrm{~cm}$, and the direction is vertically downward. On the slope surface, the displacement caused by excavation is relatively large, $0-7.1 \mathrm{~cm}$ in $X$ direction and $3-14.3 \mathrm{~cm}$ in $Z$ direction. It is mainly due to the rebound deformation towards the excavation face. But in the local area, the displacement direction is backward the excavation face, which is about $0-3 \mathrm{~cm}$. Analysis of the rock displacement changes in the $X$ and $Z$ directions caused by excavation at this step reveals that cracks due to tension and uneven subsidence will appear at the top of the slope, the whole slope is in the process of compressive yielding, and due to the impact of intense excavation and unloading, the middle and lower rock masses will undergo lateral deformation, and the slope will show a failure characteristic of "slipbend-shear".

Fig.8 (c) is the nephogram of the slope plastic area caused by the excavation at this stage. The results show that there are obvious plastic failure zones in the western area of the slope, which especially concentrated in the area near the excavation face, and the plastic zones on slope top and slope toe are connected, but the eastern area only has scattered plastic zones on the excavation face. This is mainly because the actual excavation has a relatively small impact on the disturbance of the slope, which is consistent with the actual excavation.

1. Minimum principal stress nephogram

2. Maximum principal stress nephogram

(a) Stress nephogram

1. Displacement nephogram in $X$ (strike) direction

2. Displacement nephogram in $Z$ (height) direction

(b) Displacement nephogram 
(c) Nephogram of the slope plastic area

Fig.8 Simulated results of stage 1

(3) Stage 2. Firstly, the benches at the elevation of 2190, 2160, 2130, 2100 and 2070m shall be unloaded by steps. Then, the slope shall be excavated to the elevation of $1935 \mathrm{~m}$.

Comparing Fig.9 (a) with Fig.8 (a), it can be seen that the excavation at this stage significantly reduces the tensile stress zones at the top of the slope to $0.22 \mathrm{MPa}$. In the excavation area, the maximum principal stress is compressive stress, and the stress in deep rock masses does not change much. Tensile stress concentrated zones appear at the toe of slope, benches and shoulder of slope. Although part of the tensile stress is unloaded in this stage, the slope continued to extend downward for 100 meters.

Therefore, the rock masses are still under tension, and tensile cracks are easily formed on the surface $\llbracket$ toe of slope and benches, which is consistent with the actual excavation.

Fig.9 (b) shows that after excavating by steps, the overall displacement of the slope increases greatly. Xdirection displacement in the top and the east of the slope is into the slope, and the variation range is 0 $37.1 \mathrm{~cm}$. X-direction displacement in the east of the slope is toward the excavation face, and the variation range in the upper part is $20-80 \mathrm{~cm}$, in the lower part is $100-120 \mathrm{~cm}$. Z-direction displacement in the east of the slope is due to the rebound deformation towards the excavation face, and the variation range is 0 $12.3 \mathrm{~cm}$. Z-direction displacement in the west of the slope is vertically downward, and the variation range is $20-107 \mathrm{~cm}$.-

Compared with Fig.8 (b), although the overall displacement of the slope has increased, the trend of the deformation and failure induced by the stage 1 is effectively suppressed, so that the mine can be safely excavated to the elevation of $1935 \mathrm{~m}$.

Fig.9 (c) is the nephogram of the plastic zones caused by the excavation at this stage. It shows that: the plastic zones at the pit bottom of the eastern area of the slope is concentrated, but there is no large range of plastic zones on slope surface, it only scattered on individual benches. However, the slope of the western part has a large range of plastic zones, which extend from the top to the toe of the slope. The rock masses became in plastic state, which is more likely to undergo failure. In other words, the cracks, landslides and collapse are easy to generate in local areas, which is consistent with the actual situation.

1. Minimum principal stress nephogram

2. Maximum principal stress nephogram

(a) Stress nephogram

1. Displacement nephogram in X (strike) direction

(2) Displacement nephogram in Z (height) direction 
(b) Displacement nephogram

(c) Nephogram of the slope plastic area

Fig.9 Simulated results of stage 2

\section{Analysis of planned excavation}

(1) Stage 3. The slope is mined from the elevation of $1935 \mathrm{~m}$ to $1910 \mathrm{~m}$.

Fig.10 (a) shows that during this stage, the maximum principal stress of the slope is significantly smaller than the current slope, and its value ranges from 0 to $2 \mathrm{MPa}$, which still appears as compressive stress. But the maximum principal stress on the top of slope is tensile stress of which variation range is 0 $0.98 \mathrm{MPa}$, and there is a clear tensile stress concentration zone. The minimum principal stress of the excavation face is significantly larger than the current slope, and the maximum value increases from 0.22(in stage 2) to $0.36 \mathrm{MPa}$ and appears as tensile stress. In the eastern part of the slope, the tensile stress concentration zones appear. In the western part, the tensile stress concentration zones are further expanded on the basis of stage 2. Therefore, the large-scale tensile stress concentration zones on the excavation face makes the rock masses in tension state. At the same time, because the tensile strength of the rock masses is far less than the compressive strength, the rock masses of the slope will undergo "slip-pull" failure. When the slide surfaces are connected in the internal part of the slope, the whole slope will be in a state of instability.

Fig.10 (b) reflects the variation of slope displacement in this stage. As the excavation continues downward, the displacements in the $X$ direction and the $Z$ direction increase sharply. Compared with the current slope displacement nephogram Fig. 9 (b), the maximum horizontal displacement increases from $126 \mathrm{~cm}$ to $200 \mathrm{~cm}$, and the displacement direction near the excavation face is towards the free face. The displacements in the $Z$ direction of the excavation area are all vertically downward. The maximum displacement of the slope top varies in the range of $140-182 \mathrm{~cm}$, and the overall slope subsidence is obvious.

1. Minimum principal stress nephogram

2. Maximum principal stress nephogram

(a) Stress nephogram

1. Displacement nephogram in X (strike) direction

(2) Displacement nephogram in Z (height) direction

(b) Displacement nephogram

Fig.10 Simulated results of stage 3 
(2) Stage 4, The slope is mined from the elevation of $1910 \mathrm{~m}$ to $1840 \mathrm{~m}$.

Fig.11 (a) is the maximum principal stress and minimum principal stress nephogram when excavating to the elevation of $1840 \mathrm{~m}$. It shows that as the slope continues to be excavated downward, a tensile stress zone appears at the top of the slope, and the tensile stress ranges from 0 to $0.98 \mathrm{MPa}$. The maximum principal stress in the excavation face is still compressive stress, and its value ranges from 0 to $2 \mathrm{MPa}$. The minimum principal stress of the excavation face in this stage is larger than when mining to the elevation of $1910 \mathrm{~m}$ (stage 3; Fig.10 (a)), and it increases from 0.36MPa to $0.41 \mathrm{MPa}$, which appears as tensile stress, and the tensile stress concentration zones remained on the benches of the eastern slope and the shoulders of the western slope. This indicates that the rock masses of the slope have been under tension during this stage, which causes the tensile failure to be more intense. Therefore, the overall stability of the slope is even worse.

Fig.11 (b) shows that the displacements in the $X$ direction and the $Z$ direction caused by the excavation at this stage are significantly larger than the last. Compared with Fig.10 (b), the displacement of the rock masses in the $X$ direction of local area in eastern slope at the elevation of 1940-1950m increase significantly, and the maximum value is sharply increased from $200 \mathrm{~cm}$ in stage 3 to $700 \mathrm{~cm}$. In other words, the deformation of the eastern slope area at this stage are intensified, but the overall displacement and deformation of the western slope area increased relatively slow. The displacement in Z direction of the excavation face is still vertically downward, which is also significantly larger than the last stage, and the maximum displacement increment is $717 \mathrm{~cm}$. Therefore, it can be seen that the displacement of $X$ and $Z$ direction in this stage increased significantly, which causes much intenser deformation of the whole slope.

1. Minimum principal stress nephogram

2. Maximum principal stress nephogram

3. Stress nephogram

4. Displacement nephogram in X (strike) direction

(2) Displacement nephogram in Z (height) direction

(b) Displacement nephogram

Fig.11 Simulated results of stage 4

Table 1 Physical and mechanical parameters of rock mass for Jianshan phosphorite mine 


\begin{tabular}{|lllllll|}
\hline Lithology & $\begin{array}{l}\text { Unit weight } \\
/\left(\mathrm{g} / \mathrm{cm}^{3}\right)\end{array}$ & $\begin{array}{l}\text { Tensile } \\
\text { strength } \\
/ \mathrm{MPa}\end{array}$ & $\begin{array}{l}\text { Deformation } \\
\text { modulus } / \mathrm{GPa}\end{array}$ & $\begin{array}{l}\text { Cohesion } \\
/ \mathrm{MPa}\end{array}$ & $\begin{array}{l}\text { Friction } \\
\text { angle } /{ }^{\circ}\end{array}$ & $\begin{array}{l}\text { Poisson } \\
\text { ratio }\end{array}$ \\
\hline Black shale & 2.60 & 0.09656 & 2.6269 & 0.1019 & 33.8 & 0.27 \\
\hline Ore body & 2.72 & 0.06389 & 2.7646 & 0.0610 & 27.8 & 0.23 \\
\hline $\begin{array}{l}\text { Sandy } \\
\text { dolomite }\end{array}$ & 2.76 & 0.1307 & 3.5947 & 0.1191 & 29.9 & 0.23 \\
\hline $\begin{array}{l}\text { Fine-grained } \\
\text { dolomite }\end{array}$ & 2.81 & 0.2589 & 4.8193 & 0.3186 & 43.4 & 0.22 \\
\hline
\end{tabular}

\section{Deformation And Failure Regulations}

The slope displacement increases sharply with the step-by-step excavation. Due to the steep slope angle, middle-upper rock masses are easy to slide downwards under the action of self-weight. As a result, many cracks at the top and the surface of the slope, uneven settlement, landslides and collapses in local areas are induced. The lower rock mass with a slower slope angle gradually expands and bends toward the air face under the compression of the middle-upper rock masses. When the amount of bending deformation exceeds the limit, the rock mass will undergo shear failure along the direction of the rock layer's maximum curvature, which causes the overall slope instability.

It can be seen that step-by-step excavation induced high and steep layered rock slopes with upper steep and lower gentle style to appear "slip-bend-shear" failure characteristic.

Based on the results of geological surveys and 3D numerical simulations, the entire deformation and failure process of this slope can be summarized as "unloading deformation $\rightarrow$ tensile deformation $\rightarrow$ compression bending deformation $\rightarrow$ shear failure".

Unloading deformation: Undergoing a long period of tectonic movement, the original state slope is basically in an equilibrium state. When the slope is disturbed by excavation, the unloading effect will occur towards the free face, which will cause the slope surface to deform and the tensile cracks approximately parallel to the bedding plane to appeal. With the gradual intensification of the unloading effect, the tensile cracks gradually develop downward, and the strength of the rock masses decrease rapidly.

Tensile deformation: The internal stress of the slope is adjusted, stress concentration zones appeared on the slope top and middle-upper areas. Additionally, near-surface physical, chemical, and biological weathering reactions caused the strength to further decrease (Fischer et al. 2010) and plastic failure occurred. The range of the plastic zones gradually expands for the excavation. Therefore, the middleupper rock masses with steep slope angles undergo tensile deformation and large-scale cracks appear at the top of the slope. 
Compression bending deformation: Cracks at the top of the slope are generated, and the middle-upper rock masses with steep slope angles slide down under the action of self-gravity and continue to extend downward, which causes the middle-upper slide surfaces to be connected. At the same time, the compression caused the lower rock mass with a slower slope angle to gradually bulge and bend to the free face, and cracks appeared. With the further development of slope deformation induced by the stepby-step excavation, the cracks gradually expanded and connected, and the shear outlets at the leading edge of the slope appeared intermittently, but the overall slide surface of the slope was not all connected.

Shear failure: With the continuing excavation action, the deformation of the slope is further intensified. The intense shear deformation caused the gradual connection of the shear outlets at the leading edge of the slope, which caused the slide surface to connect from top to bottom. Therefore, the slope enters the stage of overall instability, and it is easy to slide downward on a large scale.

In order to analyze the type of potentially most dangerous slide surface, a typical geological section located in the middle of the slope (Fig.2) was selected to analyze the displacement field and shear strain rate during the excavation process. The results are shown in Fig.12 and 13.

Fig.12 Displacements field

Fig.13 Shear strain rate

It can be seen from Fig.12-13 that both the displacement vector and the shear strain rate of the rock mass in the middle-upper slope are parallel to the slope surface and downward, while the displacement vector and shear strain rate of the rock mass at the lower part and the toe of the slope are approximately horizontal. Therefore, the middle-upper part of most dangerous slide surface is plane and the lower part is arced. It can also be confirmed by the slope displacement vector analysis results from Jianshan phosphate rock slope on-line real-time monitoring (Fig. 14)(Sun 2014).

Fig.14 Slope displacement vector analysis results

\section{Limitations and future works}

In this slope, there are many rock mass discontinuities, and therefore the slope stability is influenced by these discontinuities. For the stratum with major discontinuities will be excavated, they have little influence on the final slope stability. The numerical simulation is simplified and without considering rock mass discontinuities. How rock mass discontinuities influence slope stability needs to be further analyzed.

Although the rock masses mechanical parameters of Jianshan phosphate rock slopes were estimated through empirical estimation and engineering geological analogy (Table 1), excavation is a dynamic process. These parameters were changing during the excavation process. How to analyze the variation law and range of rock masses mechanical parameters in the process of slope excavation is an important 
basis for the correct analysis and evaluation of slope stability, and the research content in this aspect needs to be further analyzed.

The stability of slope is affected by seepage of groundwater(Deng et al. 2019). Complicated seepage process caused by excavation is not considered in this numerical model. How to consider the coupling effect of excavation and rock seepage field in slope stability analysis is an important research direction in the future.

\section{Conclusions And Discussion}

Step-by-step excavation causes obvious deformation of this slope. The entire deformation and failure process of this slope can be summarized as "unloading deformation $\rightarrow$ tensile deformation $\rightarrow$ compression bending deformation $\rightarrow$ shear failure". The deformation of the slope can be summarized as "slip-bend-shear". And most dangerous slip surface of composite-style has been developed gradually into this slope.

Under the current mining plan, the stress field formed by excavation is not conducive to slope stability. In addition, the shear and tension stress are concentrated on the top, shoulder, toe and benches of the slope. Step-by-step excavation probably fails to avoid landslide, some treatment is necessary:

(1) Weepholes and drainage ditches can be set up to reduce the influence of water on stability. At present, the lowest elevation of slope $(1930 \mathrm{~m})$ is higher than the minimum erosion basis $(1883.15 \mathrm{~m})$. However, with further excavation, the seepage of groundwater will affect the stability of slope.

(2) Reinforcing toe of the slope to increase the stability. Part of the slope was selected to checked this treatment. By limit equilibrium method, safety factor of the slope in study area was increase $16.7 \%$.

\section{Declarations}

\section{Acknowledgments}

This research was supported by the National Natural Science Foundation of China (Grant No. 41861134008), Key R\&D Program of Yunnan Province (Grant No. 202003AC100002), General Program of basic research plan of Yunnan Province (Grant No. 202001 AT070043).

\section{References}

Botero E et al. (2020) Successful prediction of slope failure in an excavation trial. Engineering Failure Analysis 109: 104392. https://doi.org/10.1016/j.engfailanal.2020.104392

Bui XN et al. (2020) Prediction of slope failure in open-pit mines using a novel hybrid artificial intelligence model based on decision tree and evolution algorithm. Sci Rep 10: 17. https://doi.org/10.1038/s41598020-66904-y 
Castro R et al. (2007) A study of isolated draw zones in block caving mines by means of a large $3 d$ physical model. International Journal of Rock Mechanics and Mining Sciences 44: 860-870. https://doi.org/10.1016/j.jirmms.2007.01.001

Chen B (2017) Finite element strength reduction analysis on slope stability based on ansys. Environmental and Earth Sciences Research Journal 4: 60-65. https://doi.org/10.18280/eesrj.040302

Chen $\mathrm{M}$ et al. (2014) New method for dynamic stability analysis of rock slope under blasting vibration based on equivalent acceleration and sarma method. Canadian Geotechnical Journal 51: 441-448. https://doi.org/10.1139/cgj-2012-0475

Chen S et al. (2020) Failure process and stability analysis of rock blocks in a large underground excavation based on a numerical method. Mathematical Problems in Engineering 2020: 4280428. https://doi.org/10.1155/2020/4280428

CHEN Y-m and XU D-p (2009) Flac/flac3d foundation and engineering examples. China Water\& Power press, Beijing

Crosta GB and Agliardi F (2003) Failure forecast for large rock slides by surface displacement measurements. Canadian Geotechnical Journal 40: 176-191. https://doi.org/10.1139/t02-085

Deng D-p and Li L (2019) Failure modes and a calculation method for a stability analysis on a layered slope with a focus on interlayer sliding. Arabian Journal of Geosciences 12: 182. https://doi.org/10.1007/s12517-019-4308-1

Deng DP et al. (2019) Stability analysis of a layered slope with failure mechanism of a composite slip surface. International Journal of Geomechanics 19: 1-16. https://doi.org/10.1061/(ASCE)GM.19435622.0001417

Deng DP et al. (2019) Stability analysis of slopes under groundwater seepage and application of charts for optimization of drainage design. Geomechanics and Engineering 17: 181-194. https://doi.org/10.12989/gae.2019.17.2.181

Du J (2014) Study on instability mode of layered slope in jianshan phosphate mine. doctor, Kunming University of Science and Technology

Eberhardt E et al. (2004) Numerical analysis of initiation and progressive failure in natural rock slopes. International Journal of Rock Mechanics Mining Sciences 41: 69-87. https://doi.org/10.1016/S13651609(03)00076-5

Fischer L et al. (2010) Assessment of periglacial slope stability for the 1988 tschierva rock avalanche (piz morteratsch, switzerland). Engineering Geology 116: 32-43.

https://doi.org/10.1016/j.enggeo.2010.07.005

Page 15/29 
Gao B (2017) North slope landslide analysis and control research in fushun west open-pit mine. Opencast Mining Technology 32: 14-16.

Gong B and Tang C (2017) Slope-slide simulation with discontinuous deformation and displacement analysis. International Journal of Geomechanics 17: E4016017. 10.1061/(ASCE)GM.1943-5622.0000746

Guo Q et al. (2020) Analysis of progressive failure mechanism of rock slope with locked section based on energy theory. Energies 13: 1128. https://doi.org/10.101610.3390/en13051128

Jing $L$ (2003) A review of techniques, advances and outstanding issues in numerical modelling for rock mechanics and rock engineering. International Journal of Rock Mechanics and Mining Sciences 40: 283353. https://doi.org/10.1016/s1365-1609(03)00013-3

Lai XP et al. (2015) Comprehensive evaluation of high-steep slope stability and optimal high-steep slope design by 3d physical modeling. International Journal of Minerals, Metallurgy Materials 22: 1-11. https://doi.org/10.1007/s12613-015-1036-8

Li LC et al. (2009) Numerical analysis of slope stability based on the gravity increase method. Computers and Geotechnics 36: 1246-1258. https://doi.org/10.1016/j.compgeo.2009.06.004

Lian XG et al. (2020) Rapid identification of landslide, collapse and crack based on low-altitude remote sensing image of uav. J Mt Sci 17: 2915-2928. https://doi.org/10.1007/s11629-020-6080-9

Liu CL et al. (2005) Development of a computer program for inhomogeneous modeling using 3-d bem with analytical integration and its application to rock slope stability evaluation. International Journal of Rock Mechanics and Mining Sciences 42: 137-144. https://doi.org/10.1016/j.ijrmms.2004.07.004

Liu $\mathrm{H}$ et al. (2020) The time-dependent failure mechanism of rocks and associated application in slope engineering: An explanation based on numerical investigation. Mathematical Problems in Engineering 2020: 1680265. https://doi.org/10.1155/2020/1680265

Michalowski RL (2013) Stability assessment of slopes with cracks using limit analysis. Canadian Geotechnical Journal 50: 1011-1021. https://doi.org/10.101610.1139/cgj-2012-0448

Santos TBd et al. (2019) Quantitative hazard assessment system (has-q) for open pit mine slopes. International Journal of Mining Science and Technology 29: 419-427.

https://doi.org/10.1016/j.jimst.2018.11.005

Sarkar K et al. (2012) A numerical simulation of landslide-prone slope in himalayan region-a case study. Arabian Journal of Geosciences 5: 73-81. https://doi.org/10.1007/s12517-010-0148-8

Satyanarayana I and Budi G (2019) Analytical and numerical approach for analysis of factors affecting pit slope stability at dorli ocp-ii, india. J Min Sci 55: 376-382.

https://doi.org/10.1134/s1062739119035696

Page 16/29 
Sun $\mathrm{H}$ (2014) Research on monitoring and prediction of rock slope for jianshan phosphorite mine. Kunming University of Science and Technology

Tao $Z$ et al. (2021) Prediction of deep rock mass quality and spatial distribution law of open-pit gold mine based on 3d geological modeling. Geotechnical and Geological Engineering 39.

https://doi.org/10.1007/s10706-021-01690-6

Vemulapalli SC and Mesapam S (2021) Slope stability analysis for mine hazard assessment using uav. J Indian Soc Remote Sens: 8. https://doi.org/10.1007/s12524-020-01239-9

Wang $\mathrm{H}$ et al. (2012) Rock slope stability analysis based on flac3d numerical simulation. Applied Mechanics and Materials 170-173: 375-379. https://doi.org/10.4028/www.scientific.net/AMM.170173.375

Wyllie DC and Mah C (2004) Rock slope engineering: Fourth edition.

Yang X et al. (2012) Comparison of strength reduction method for slope stability analysis based on abaqus fem and flac3d fdm. Applied Mechanics and Materials 170-173: 918-922. https://doi.org/10.4028/www.scientific.net/AMM.170-173.918

Yifan Z et al. (2015) Research on stability of slope of landfill site based on flac3d. International Conference on Advances in Energy, Environment and Chemical Engineering, Atlantis Press, pp 492-496

Zhang B (2009) The landslide research of haizhou open-pit mine. Liaoning Normal University

Zhou XP et al. (2019) A modified sarma method for stability analysis of layered slopes. Bulletin of Engineering Geology and the Environment 78: 1893-1909. https://doi.org/10.1007/s10064-017-1199-9

Zhu D et al. (2011) Revival deformation mechanism of hefeng landslide in the three gorges reservoir based on flac3d software. Procedia Engineering 15: 2847-2851.

https://doi.org/10.1016/j.proeng.2011.08.536

\section{Figures}




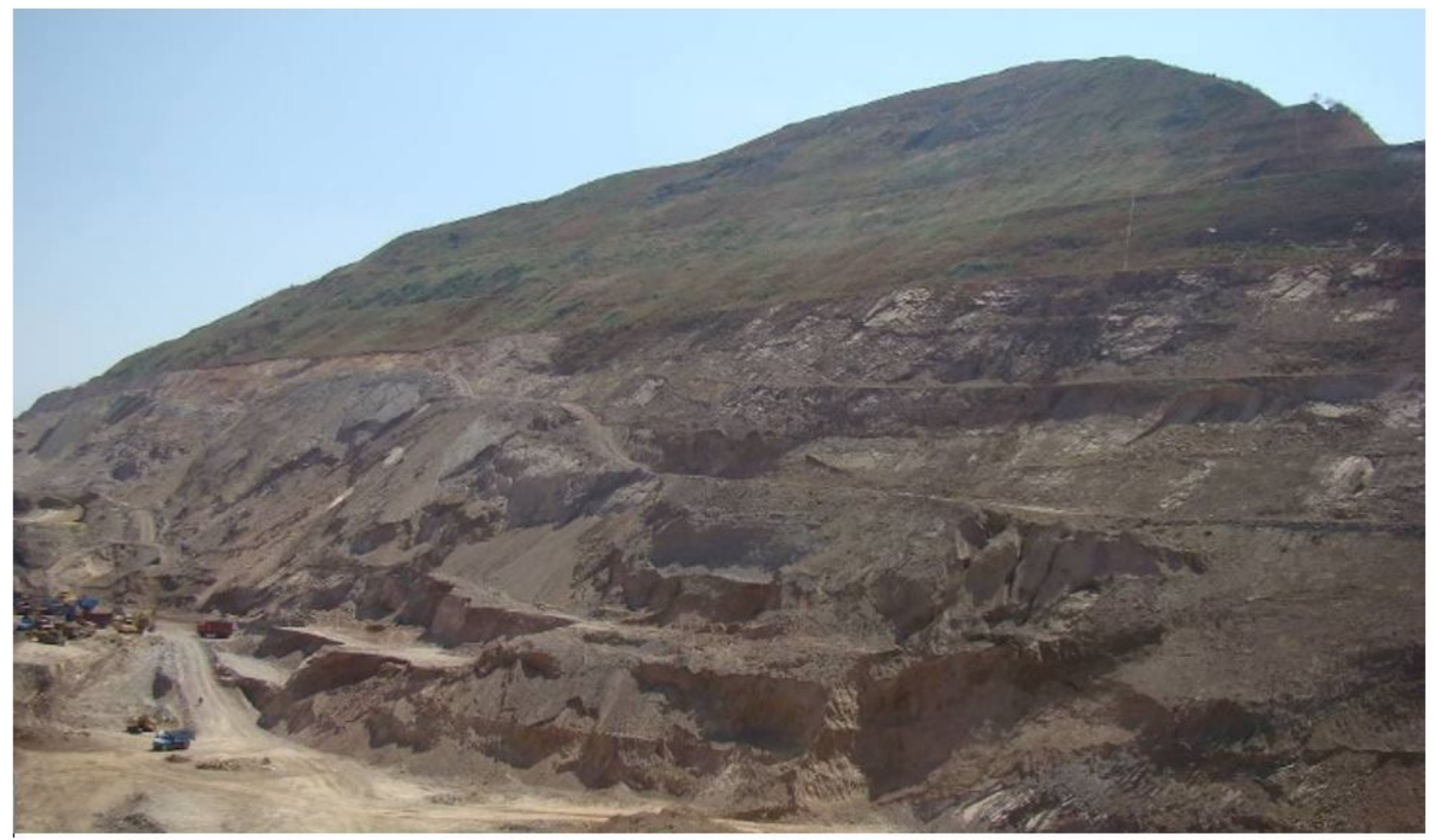

\section{Figure 1}

Close-up view of high and steep layered rock slopes belonging to Jianshan phosphorite mine

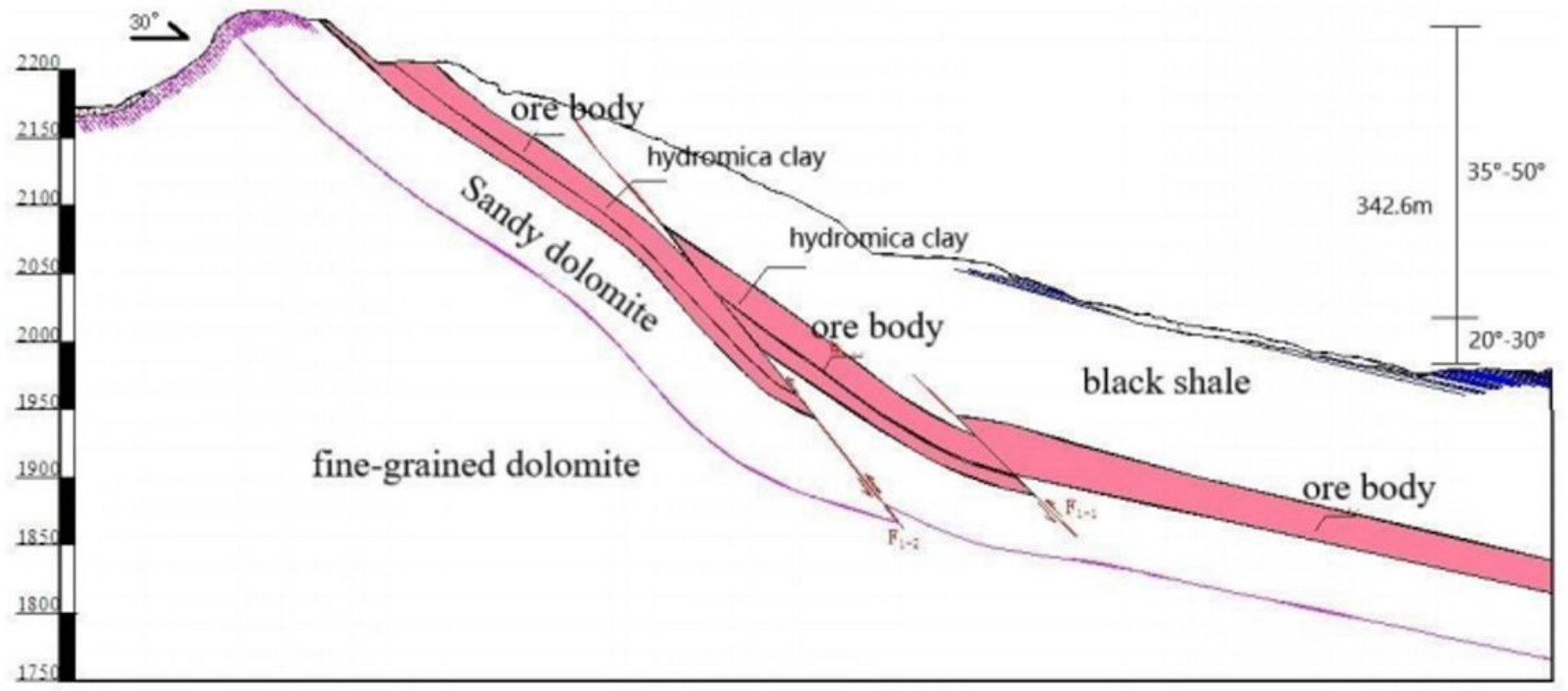

Figure 2 


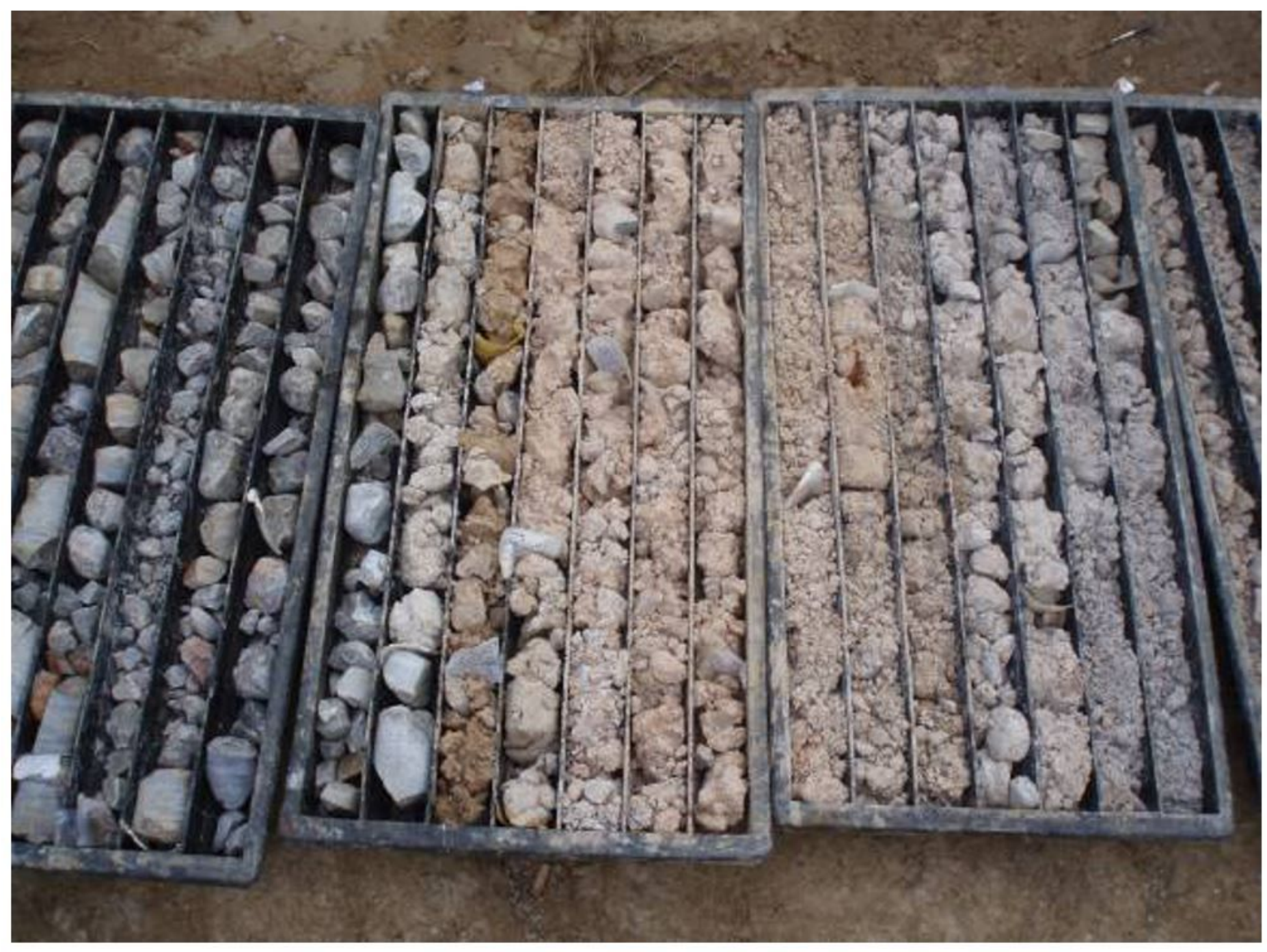

Figure 3

Rock samples by drilling in the area of Jianshan phosphorite mine 


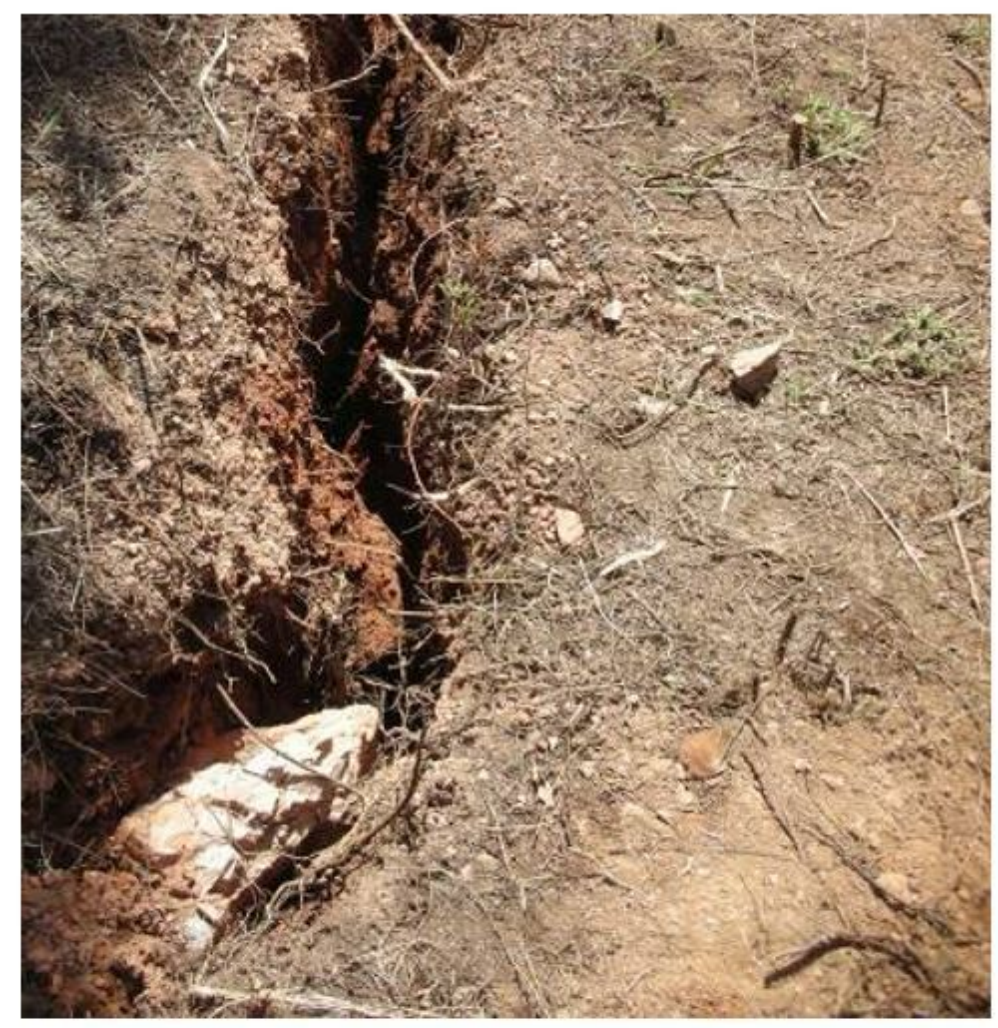

(1) The crack at the top of the slope

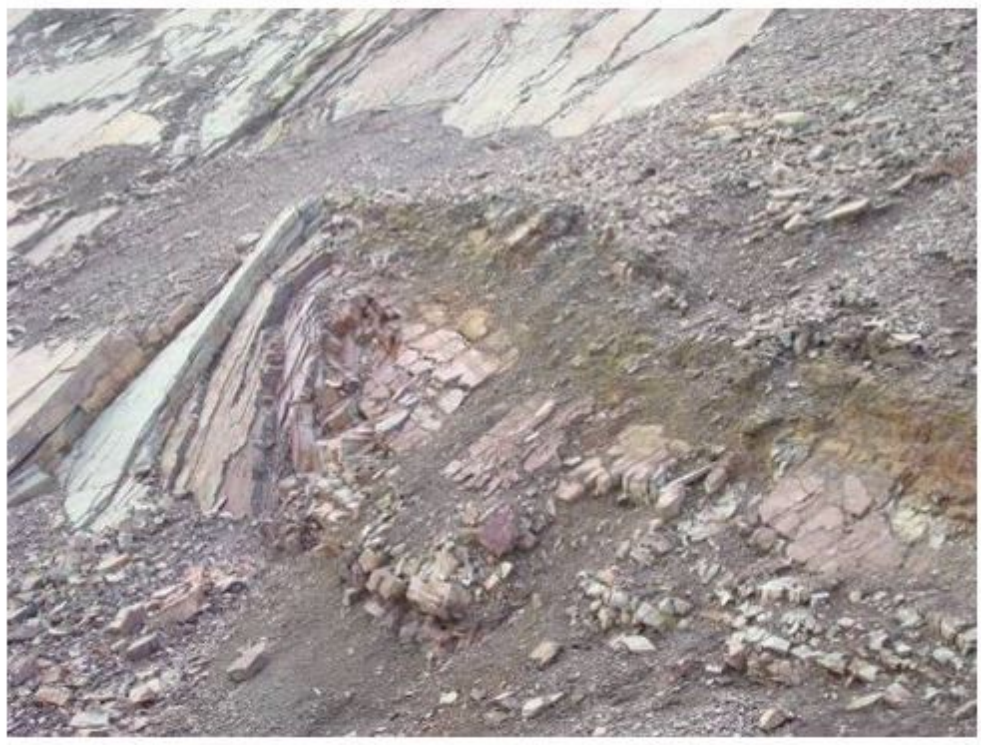

(2) Floor heave at the toe of the slope

Figure 4

Deformation and failure of Jianshan phosphorite mine excavated to $2035 \mathrm{~m}$ 


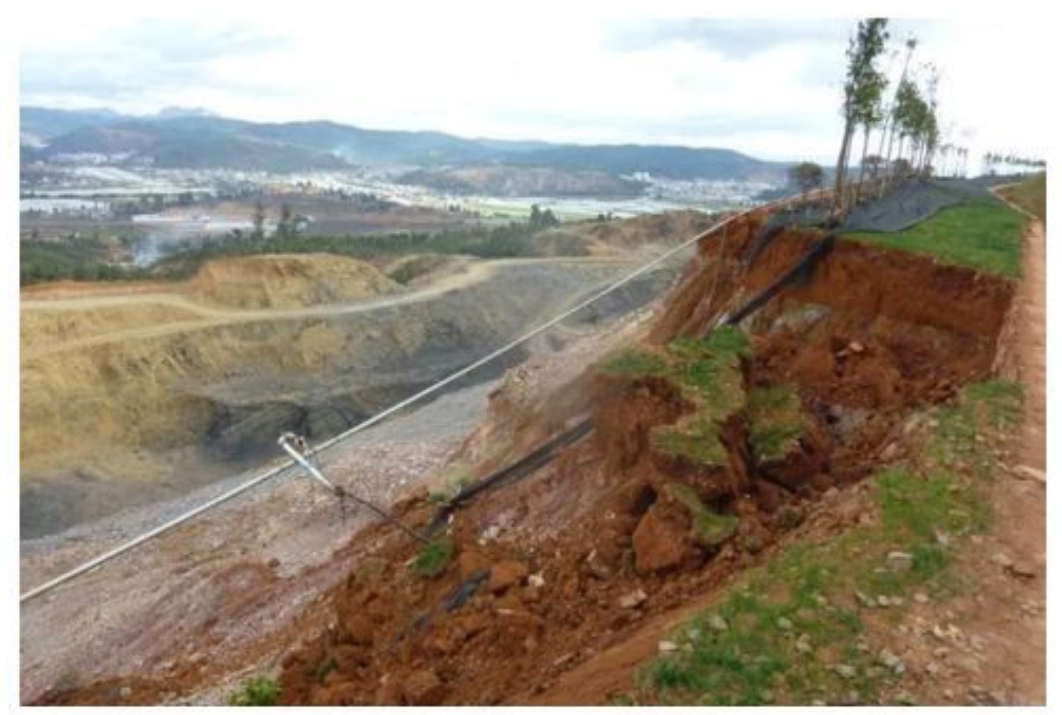

(1) A landslide happened in the bench at the elevation of $2070 \mathrm{~m}$

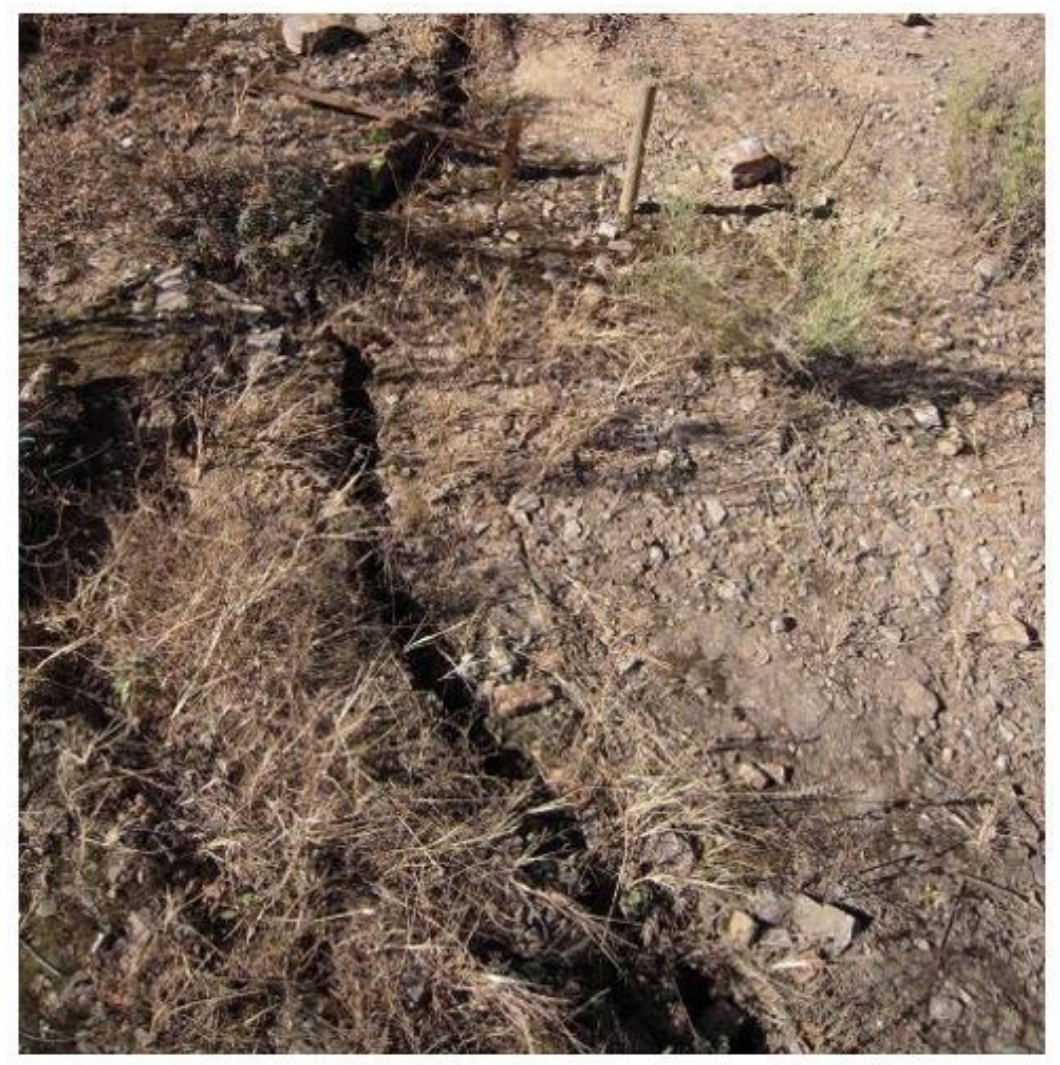

(2) A crack developed in the bench at the elevation of $2190 \mathrm{~m}$

\section{Figure 5}

Deformation and failure of Jianshan phosphorite mine excavated to 1935m (Present state) 


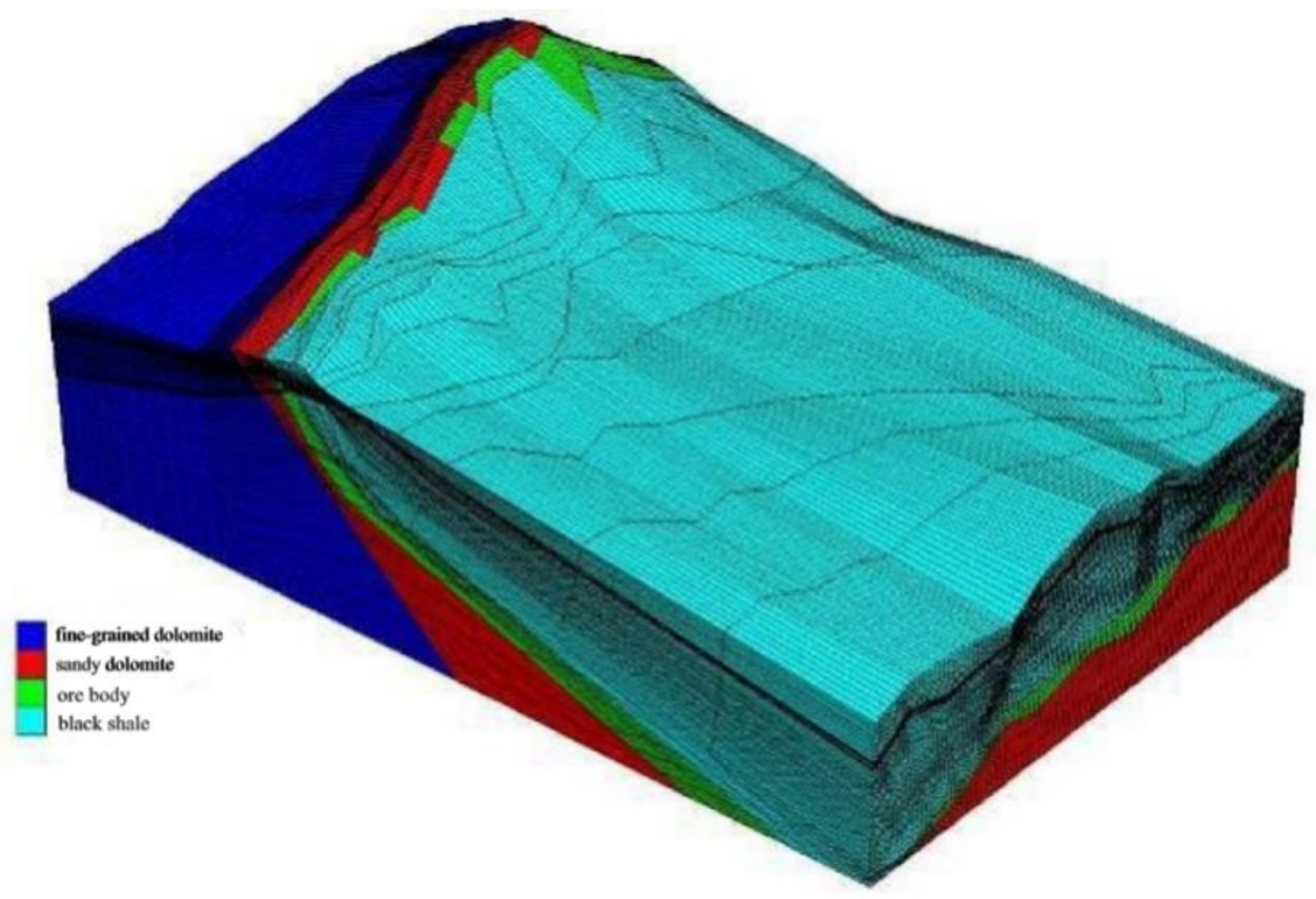

Figure 6

Original three-dimensional geological model of Jianshan phosphorite mine 


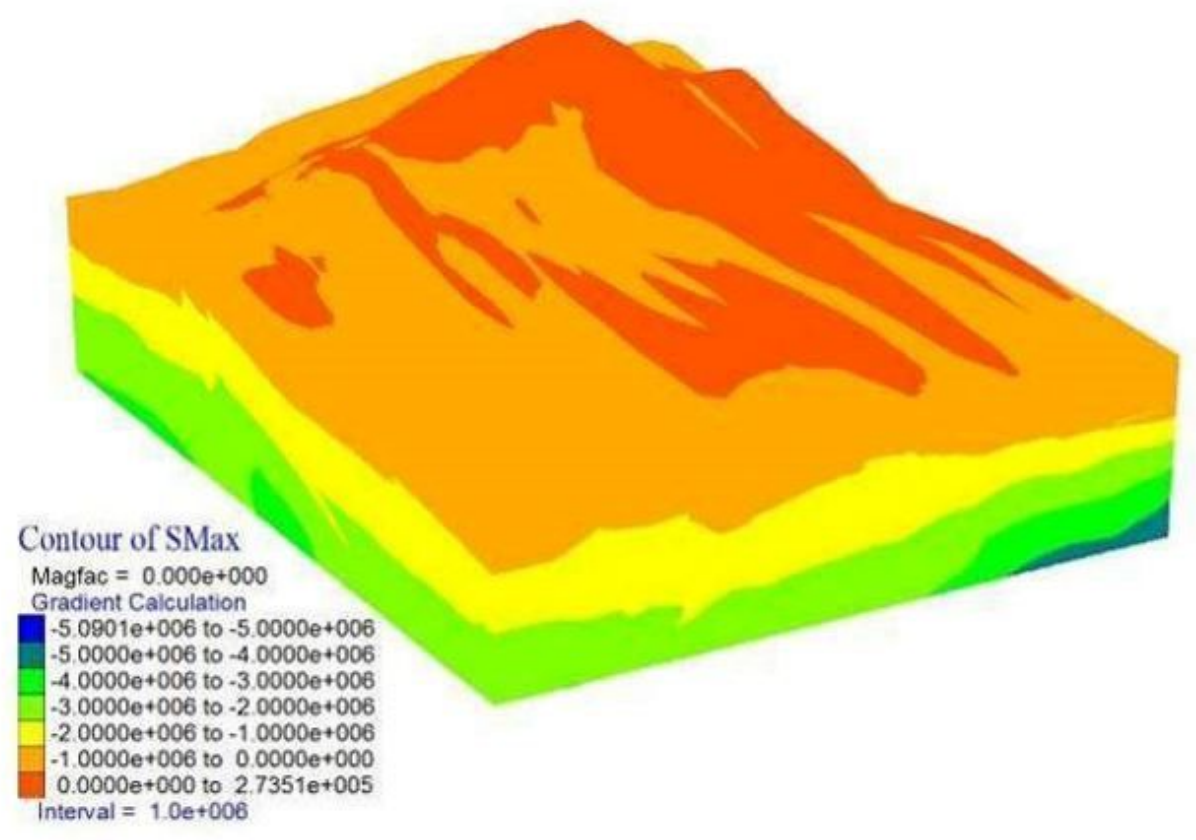

(1) Maximum principal stress nephogram

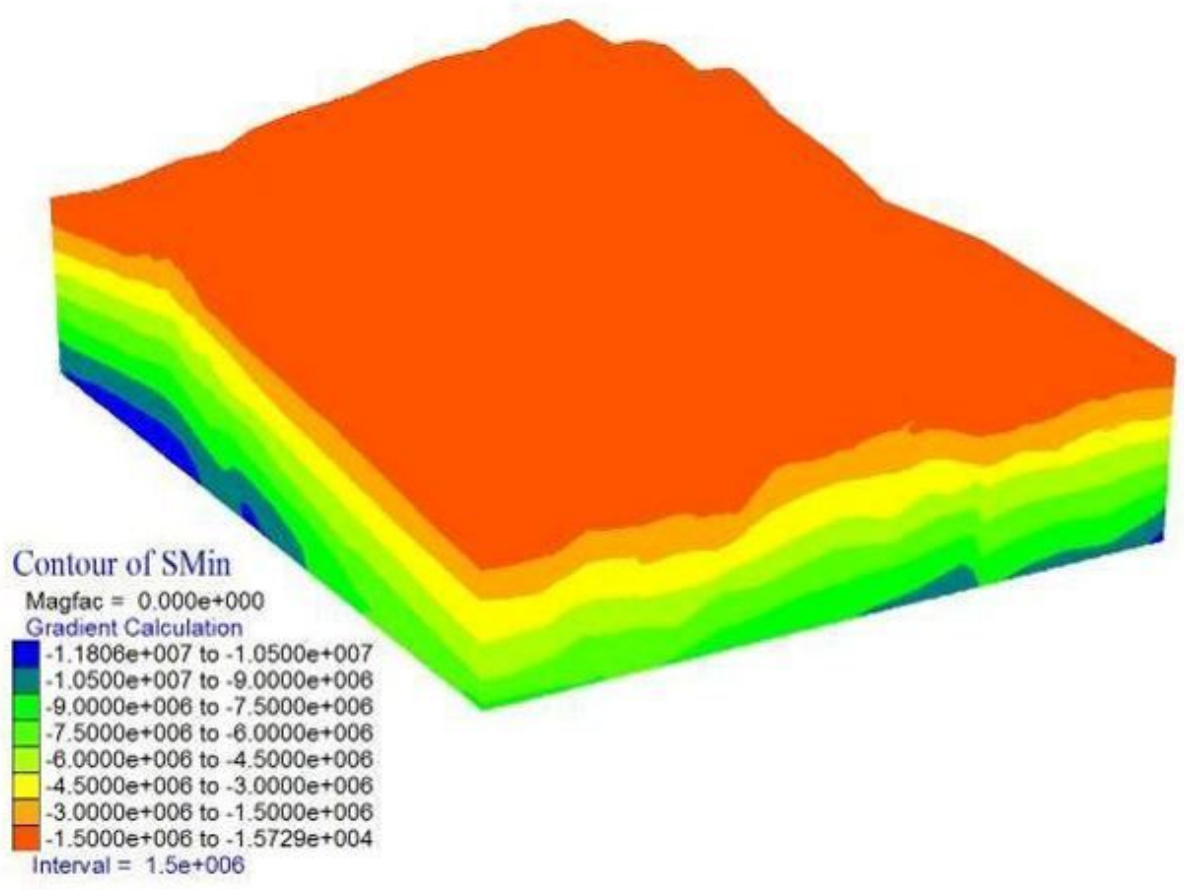

(2) Minimum principal stress nephogram

\section{Figure 7}

Stress nephogram of the slope under the original condition 


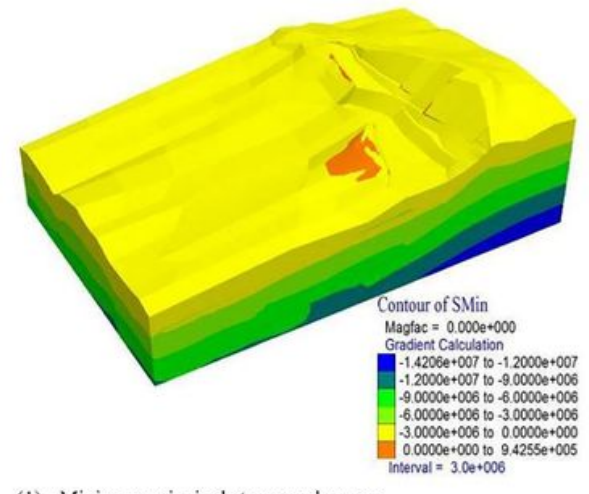

(1) Minimum principal stress nephogram

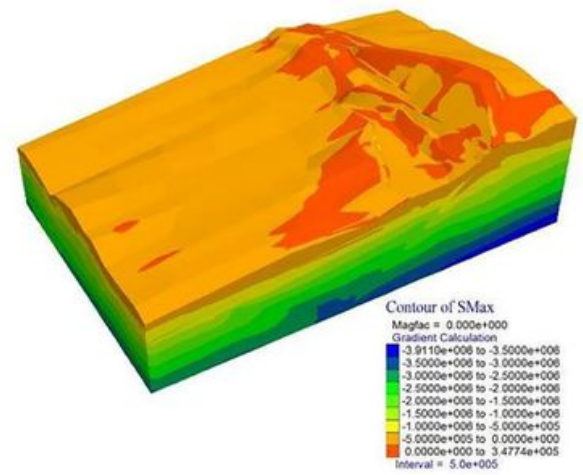

(2) Maximum principal stress nephogram

(a) Stress nephogram

\section{Figure 8}

\section{Simulated results of stage 1}

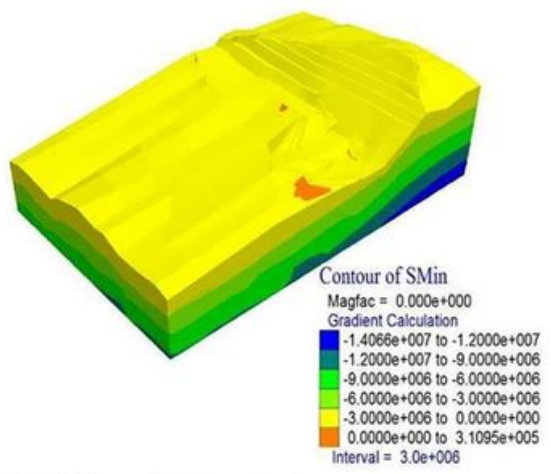

(1) Minimum principal stress nephogram

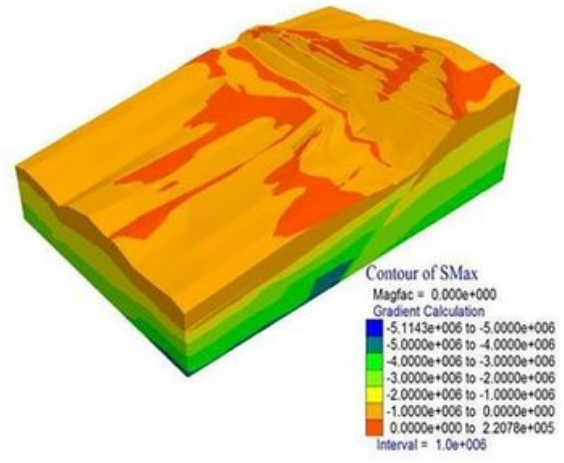

(2) Maximum principal stress nephogram

(a) Stress nephogram

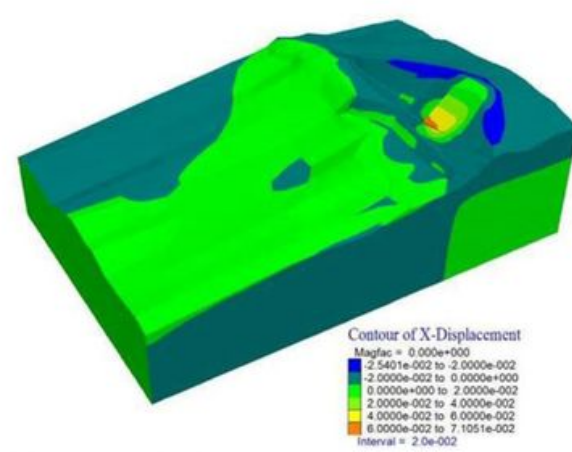

(1) Displacement nephogram in X (strike) direction

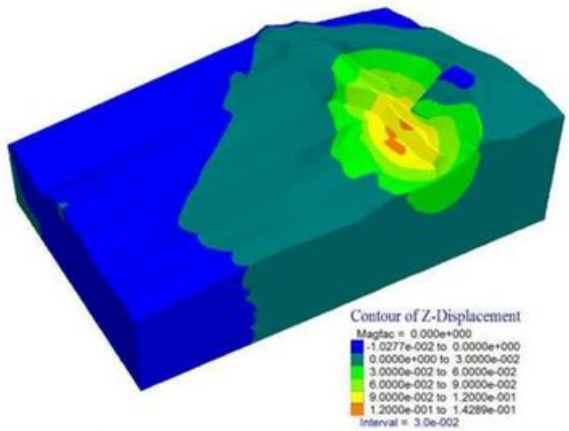

(2) Displacement nephogram in $\mathrm{Z}$ (height) direction

(b) Displacement nephogram

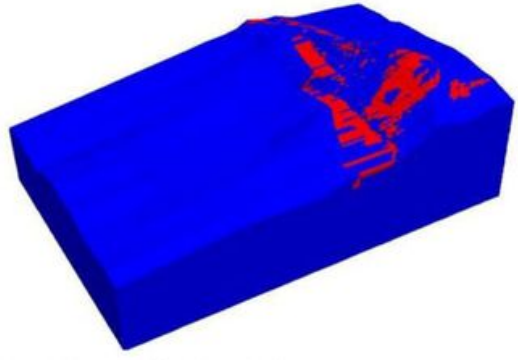

(c) Nephogram of the slope plastic area

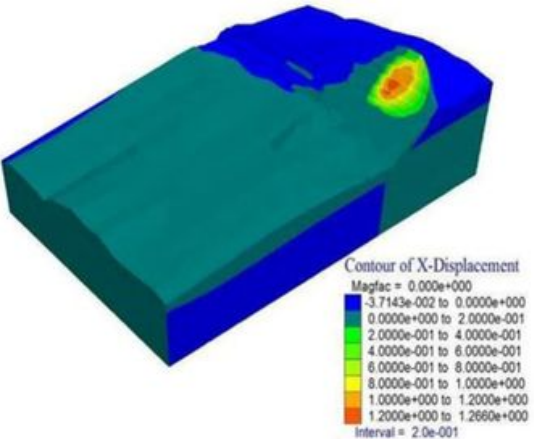

(1) Displacement nephogram in $\mathrm{X}$ (strike) direction

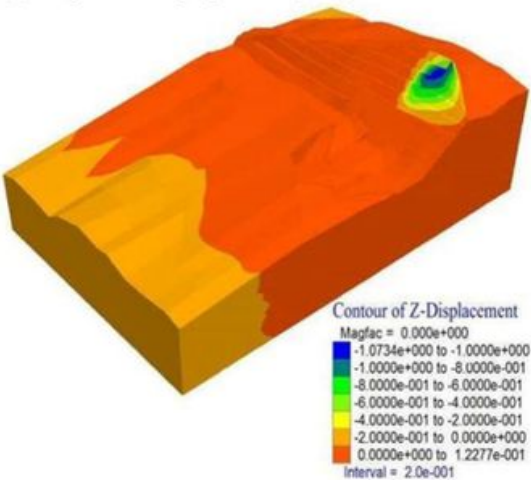

(2) Displacement nephogram in Z (height) direction

(b) Displacement nephogram

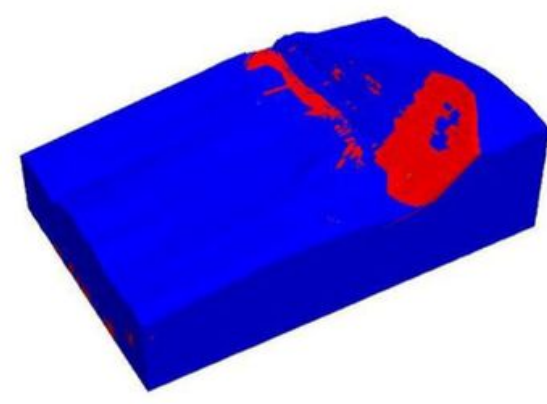

(c) Nephogram of the slope plastic area

Figure 9 
Simulated results of stage 2

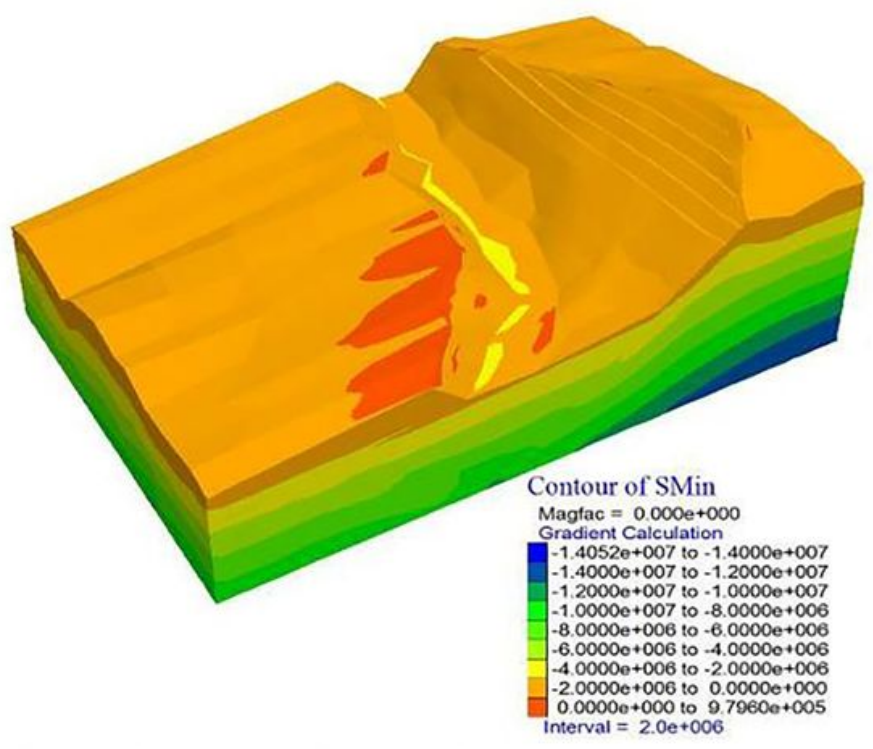

(1) Minimum principal stress nephogram

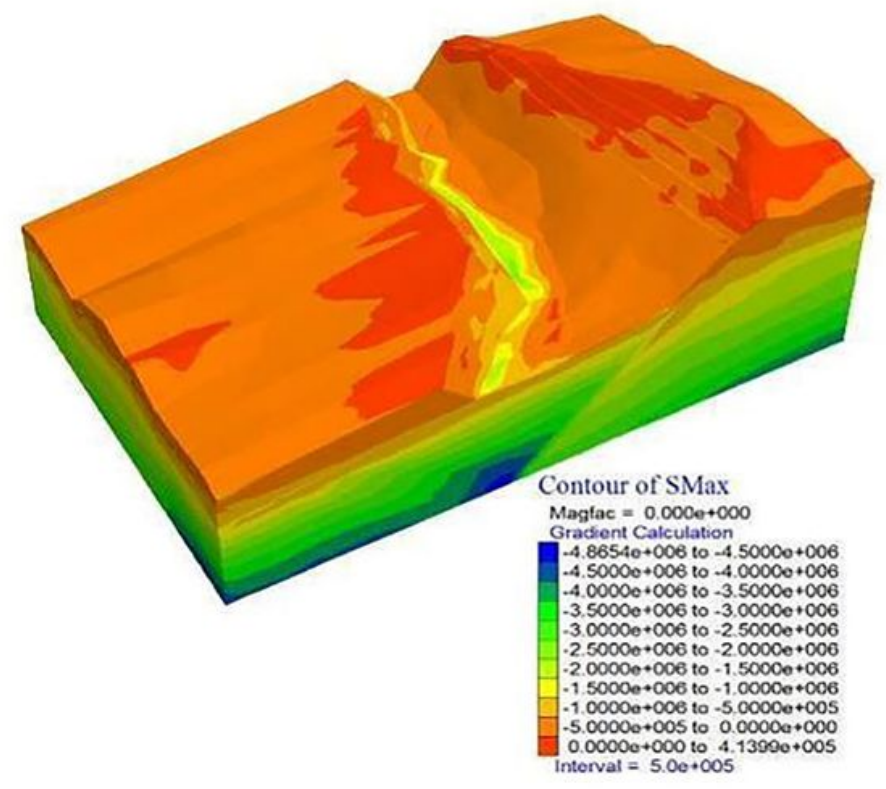

(1) Maximum principal stress nephogram

(a) Stress nephogram

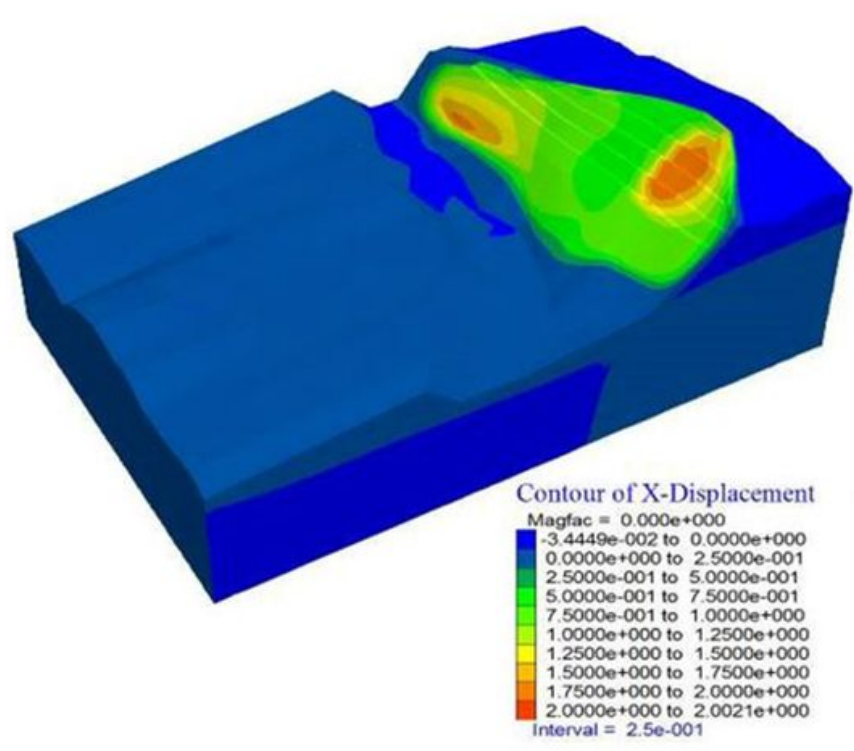

(1) Displacement nephogram in $\mathrm{X}$ (strike) direction

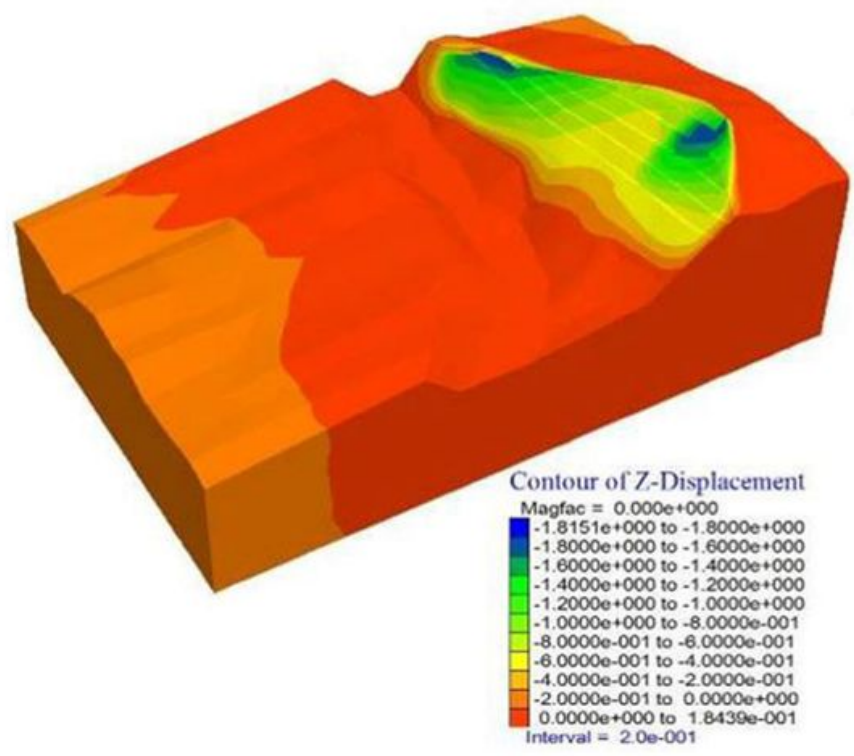

(2) Displacement nephogram in $\mathrm{Z}$ (height) direction

(b) Displacement nephogram

Figure 10

Simulated results of stage 3 


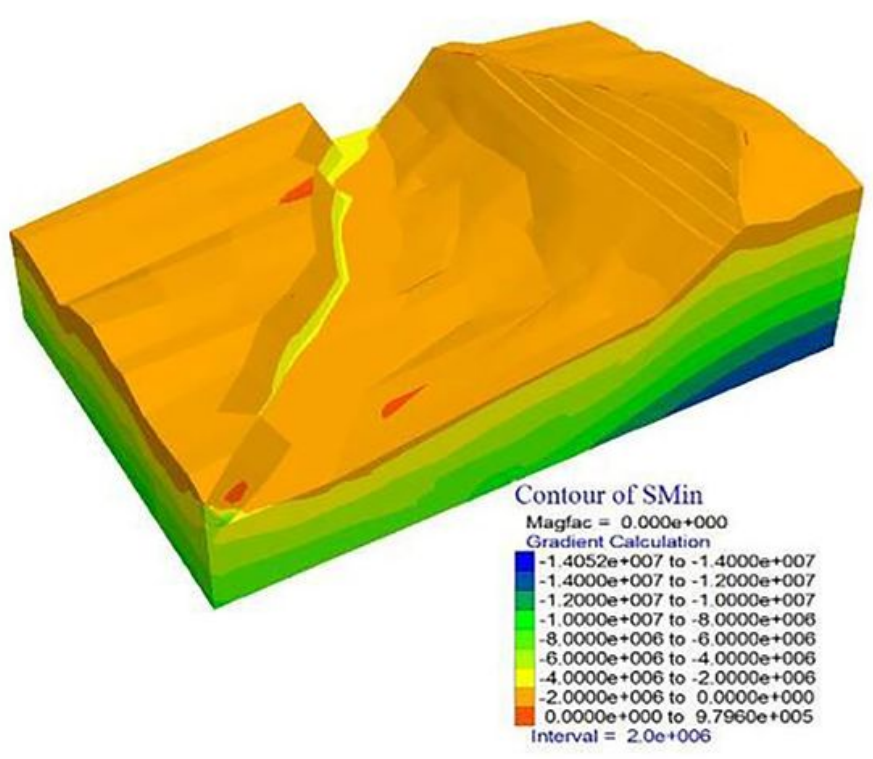

(1) Minimum principal stress nephogram

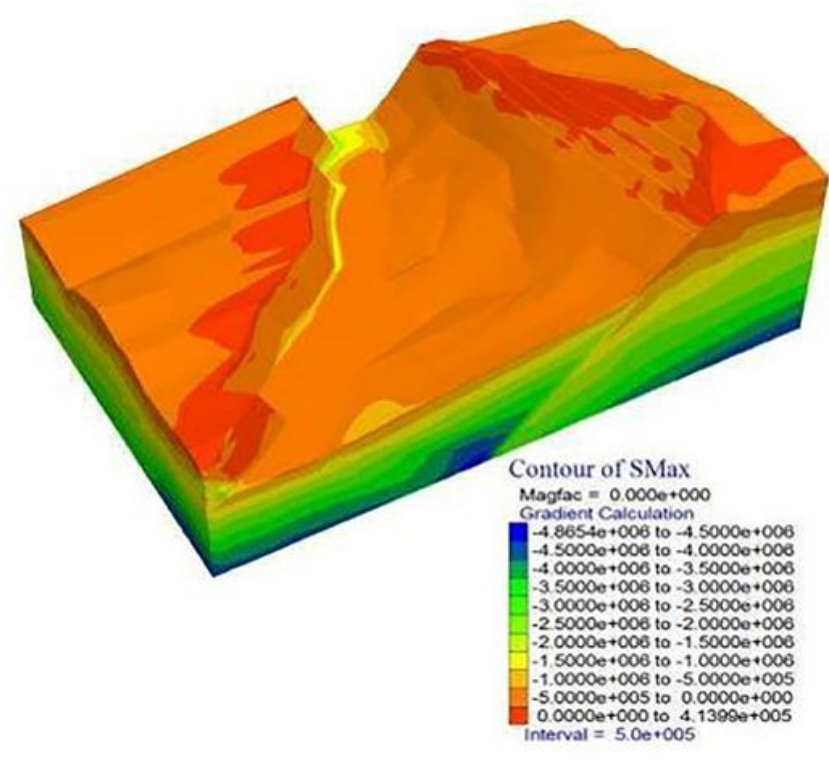

(2) Maximum principal stress nephogram

(a) Stress nephogram

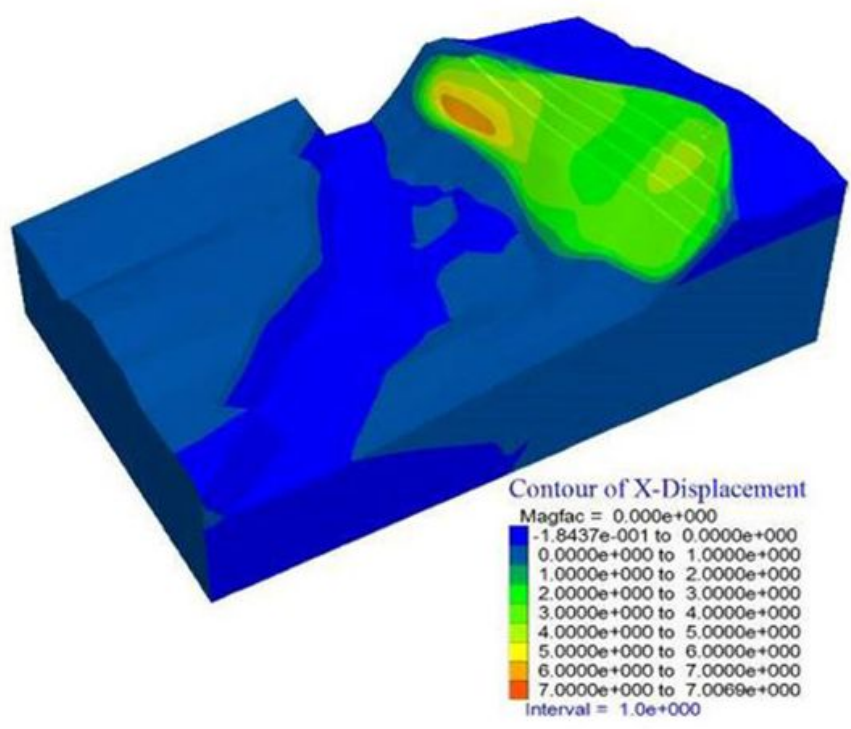

(1) Displacement nephogram in X (strike) direction

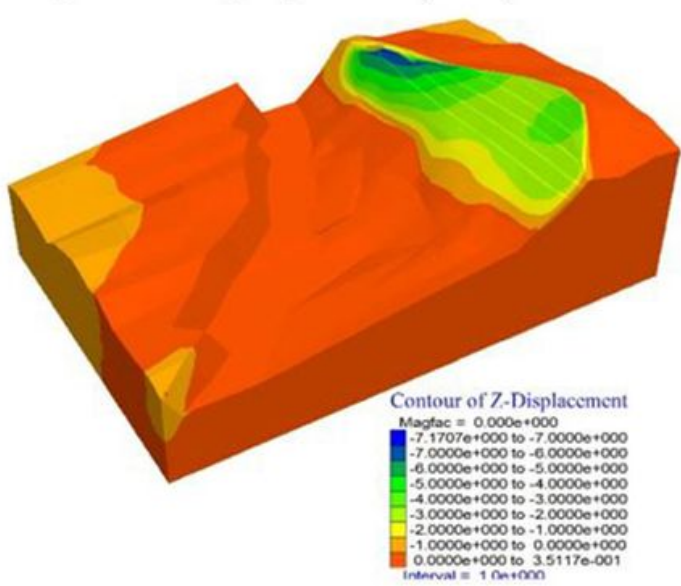

(2) Displacement nephogram in $\mathrm{Z}$ (height) direction

(b) Displacement nephogram

\section{Figure 11}

Simulated results of stage 4 


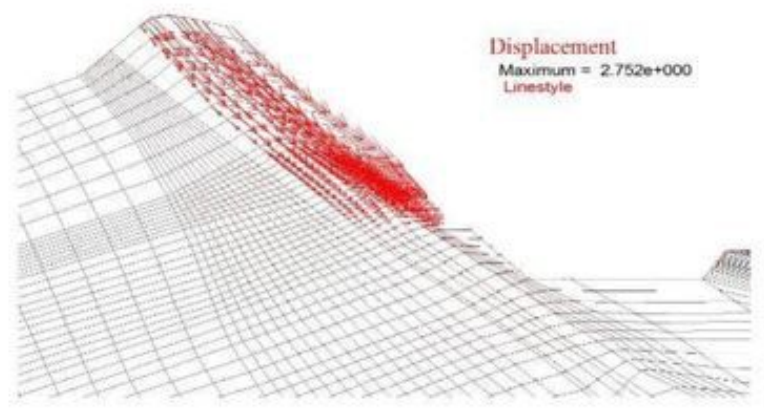

(1) Stage 1

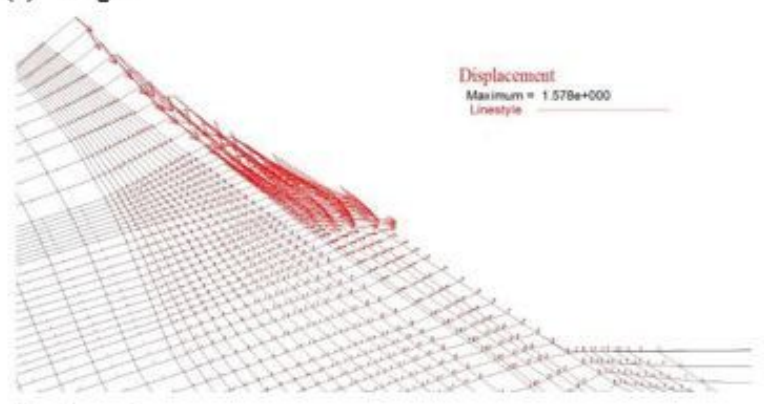

(2) Stage 2

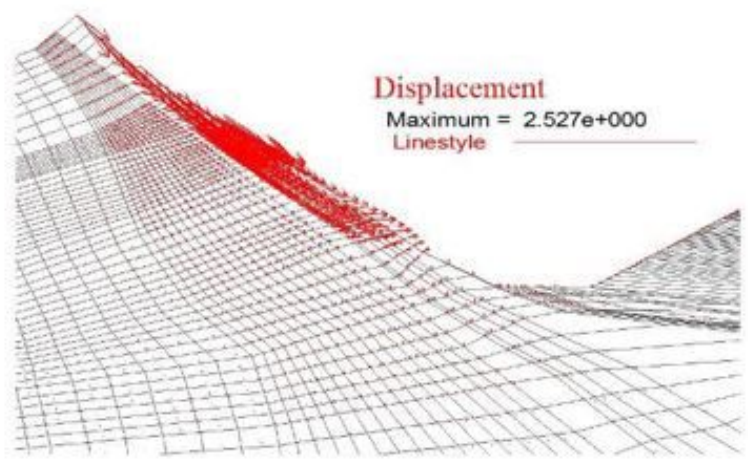

(3) Stage 3

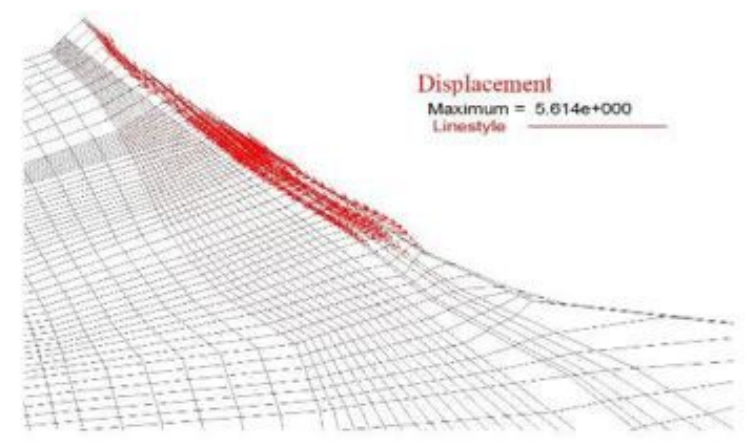

(4) Stage 4

Figure 12

Displacements field 


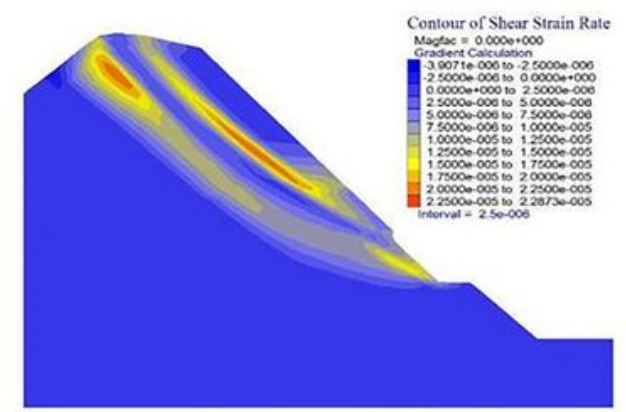

(1) Stage 1

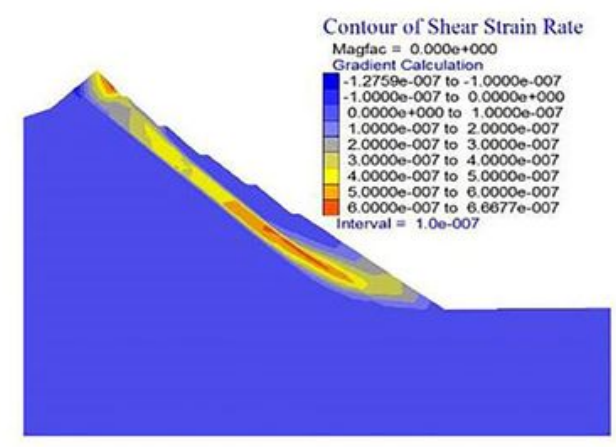

(2) Stage 2

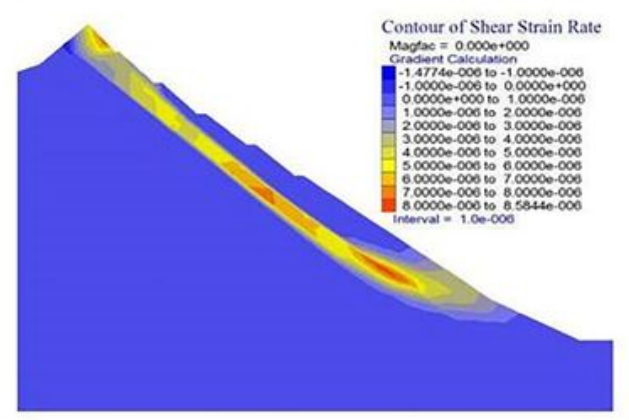

(3) Stage 3

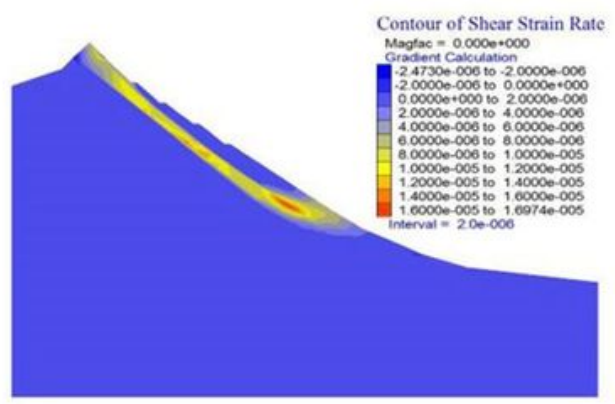

(4) Stage 4

\section{Figure 13}

Shear strain rate 


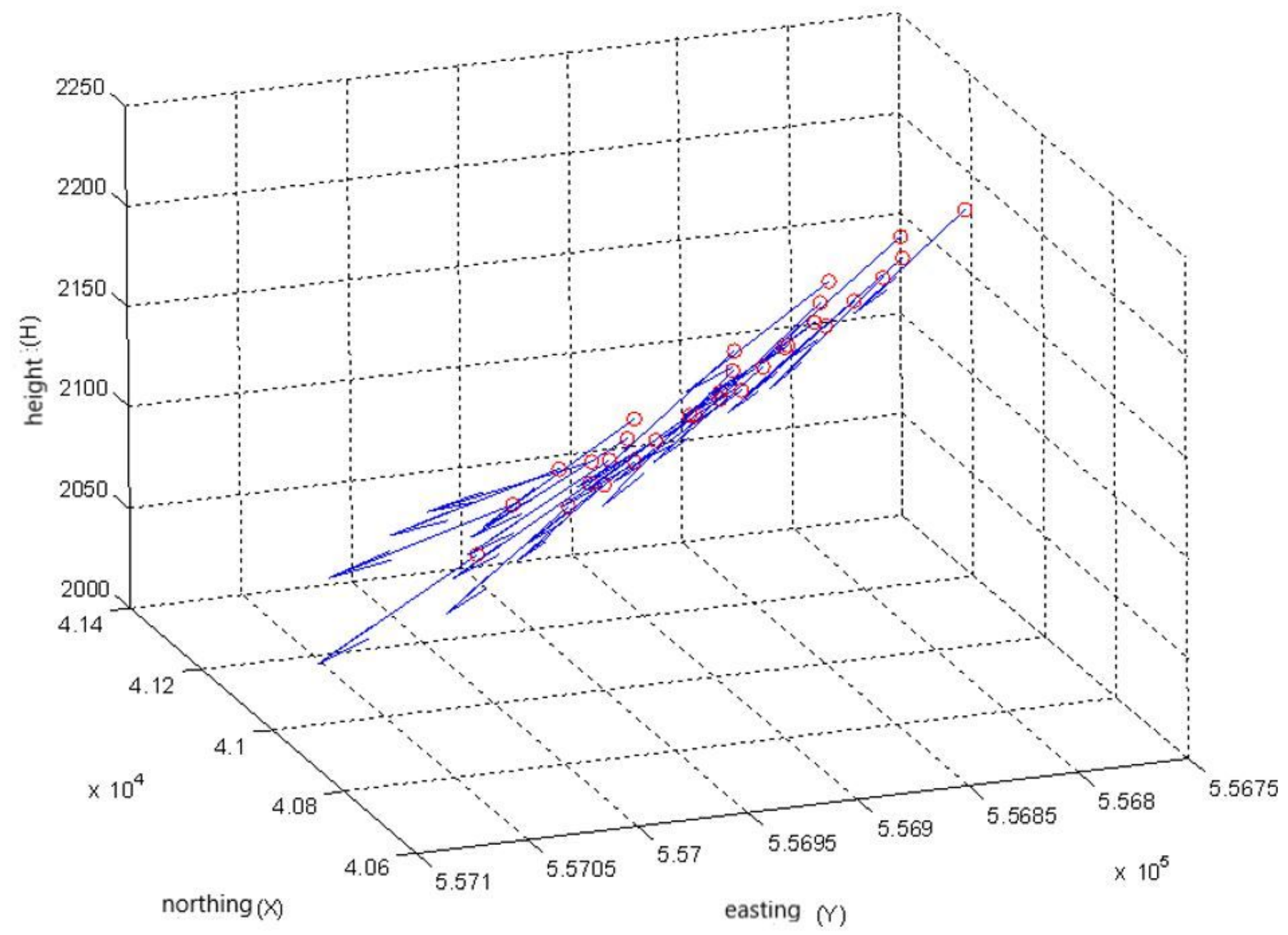

Figure 14

Slope displacement vector analysis results 